2004 December 31

Cooperative Agreement

No. DE-FC36-00ID13900

\title{
Aluminum Carbothermic Technology
}

Final Technical Progress Report for the Period 2000 July through 2004 December

Submitted to:

U. S. Department of Energy

Golden Field Office

1617 Cole Boulevard

Golden, CO 80401 
DOE/ID/13900

\title{
Aluminum Carbothermic Technology
}

\author{
Submitted to: \\ U. S. Department of Energy \\ Cooperative Agreement Number DE-FC36-00ID13900 \\ Submitted by: \\ M. J. Bruno \\ Alcoa Inc. \\ 100 Technical Drive \\ Alcoa Center, PA 15069-0001 \\ Email: marshall.bruno@alcoa.com; \\ phone: 724-337-1029 \\ Elkem ASA
}

2004 December 31

This report is based upon work supported by the U.S. Department of Energy under Award No. DE-FC36-00ID13900. Any opinions, findings, and conclusions or recommendations expressed in this material are those of the author and do not necessarily reflect the views of the Department of Energy.

This report does not contain any patentable material, protected data, proprietary data, classified information, information subject to export control classification, or other information not subject to release. 
Page No.

EXECUTIVE SUMMARY …………………………..................................

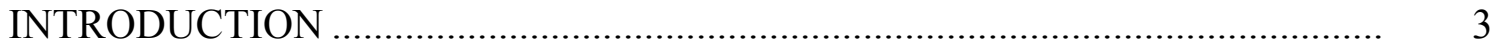

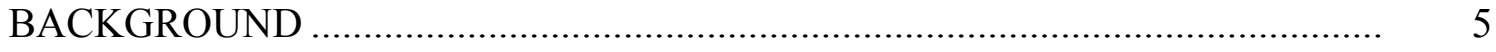

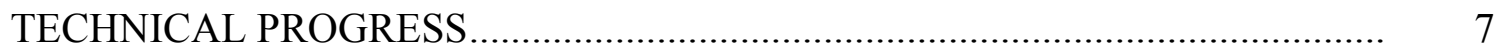

Fundamental Research ........................................................................... $\quad 7$

Slag and Metal Viscosities.......................................................................... 12

Mechanism and Rate of Reaction of $\mathrm{Al}_{2} \mathrm{O}$ and $\mathrm{CO}$ Vapors with Carbon............ 14

Vapor Pressures of $\mathrm{Al} 2 \mathrm{O}$ and $\mathrm{Al}$ in Equilibrium with $\mathrm{Al}_{4} \mathrm{C}_{3}-\mathrm{Al}_{2} \mathrm{O}_{3}$ Slag

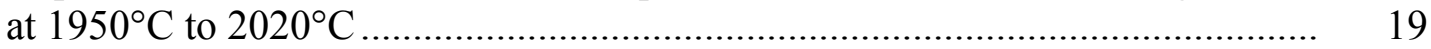

COMPUTER MODELING ….................................................................... 21

CMU Programs ...................................................................................... 21

Program A: Vapor Recovery Reactor for Carbothermic Aluminum

Production...................................................................................... 21

Model A1: Stage-wise VRR Model .................................................. 21

Model A2: Continuous Fixed Bed VRR Model .................................. 22

Model A3: Moving Bed VRR Slag Model .......................................... 22

Model A4: Total Process Model ....................................................... 22

Program B: CFD Modeling of Stage 2 of the Carbothermic Aluminum Process .......................................................................................... 22

Model B1: Thermo-physical Properties.............................................. 22

Model B2: Mixed Integer Nonlinear Programming Model for Optimal Voltage ............................................................................. 23

Model B3: CFD Model for Fluid Flow Calculation in Stage 2 ........... $\quad 23$

Alcoa Programs..................................................................................... 24

REACTOR DEVELOPMENT ……………................................................... 26

DECARBONIZATION DEVELOPMENT …………..................................... 31

ECONOMIC ANALYSIS ………………............................................. 33

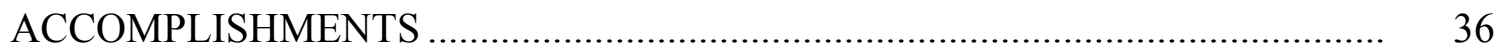

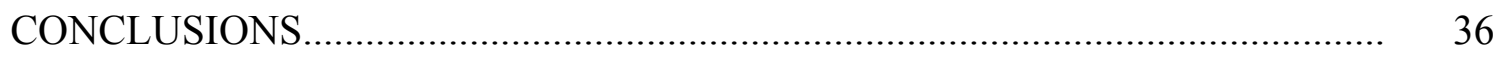

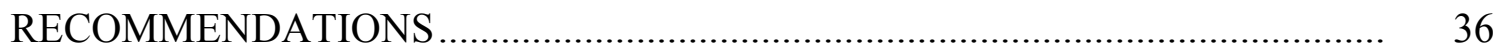

REFERENCES ............................................................................... 37

INVENTIONS/PATENT APPLICATIONS/INVENTION REPORTS ..................... 39

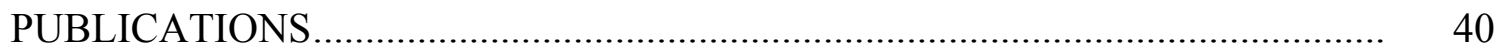

Fundamental Research ......................................................................... 40

Process Development ............................................................................ 40

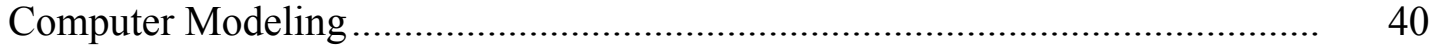




\section{List of Figures}

Page No.

Figure 1: The Pseudobinary Phase Diagram $\mathrm{Al}_{4} \mathrm{C}_{3}-\mathrm{Al}_{2} \mathrm{O}_{3}$ with Equilibrium Temperatures for the Main Phase Combinations..................................... 8

Figure 2: Alcoa Operating Diagram of the Al-C-O System.................................... 9

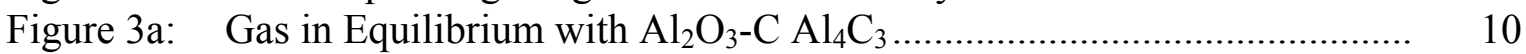

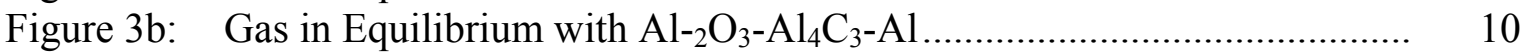

Figure 4: Flow Chart of the ACT-ARP Concept for Carbothermic Aluminum

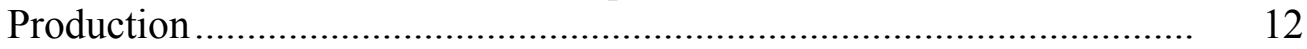

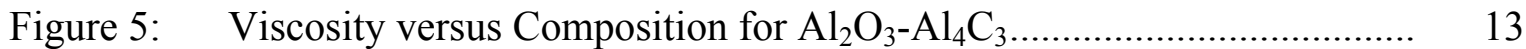

Figure 6: Viscosity versus Concentration for Al-C ...............................................

Figure 7: Schematic Diagram of Experimental Equipment ................................... 14

Figure 8a: Wood Charcoal Structure................................................................ 16

Figure 8b: Metallurgical Coke Structure ............................................................. 16

Figure 9: Reacted Wood Charcoal Indicating Carbon-Carbide Interface ................ 17

Figure 10a: Partially Reacted Wood Charcoal Showing $\mathrm{Al}_{4} \mathrm{C}_{3}$ Crystal Growth......... 17

Figure 10b: Fully Reacted Wood Charcoal ............................................................. 18

Figure 11: Dense Slag Formed on Wood Charcoal Surface...................................... 18

Figure 12: Overview of the Experimental Site for Stage 1 ................................... 26

Figure 13: Front View of the Stage 1 Reactor.......................................................... 27

Figure 14: Stage 2 Module with Lid Removed Showing Molten Slag Flow ............ 27

Figure 15: Test Site ………………………………................................... 28

Figure 16: Oil Cooling System........................................................................... 29

Figure 17: Static Bed VRR Experiment in a Single Electrode Arc Furnace............. 29

Figure 18 Converted VRR Charge ....................................................................... 30

\section{List of Tables}

Page No.

Table 1: $\quad$ Properties of the Unreacted Forms of Carbon Tested............................... 15

Table 2: $\quad$ Measured and Predicted $\mathrm{Al}_{2} \mathrm{O}_{3}$ Pressures during Slag Making ............... 20

Table 3: $\quad$ Estimated Total Cost Comparison for 400,000 MTY Al Production...... 33

Table 4: $\quad$ Estimated Total Cost Comparison for 240,000 MTY Al Production ...... 34 


\section{EXECUTIVE SUMMARY}

This report documents the non-proprietary research and development conducted on the Aluminum Carbothermic Technology (ACT) project from contract inception on July 01, 2000 to termination on December 31, 2004. The objectives of the program were to demonstrate the technical and economic feasibility of a new carbothermic process for producing commercial grade aluminum, designated as the "Advanced Reactor Process" (ARP). The scope of the program ranged from fundamental research through small scale laboratory experiments ( $65 \mathrm{~kW}$ power input) to larger scale test modules at up to $1600 \mathrm{~kW}$ power input. The tasks included work on four components of the process, Stages 1 and 2 of the reactor, vapor recovery and metal alloy decarbonization; development of computer models; and economic analyses of capital and operating costs.

Justification for developing a new, carbothermic route to aluminum production is defined by the potential benefits in reduced energy, lower costs and more favorable environmental characteristics than the conventional Hall-Heroult process presently used by the industry. The estimated metrics for these advantages include energy rates at approximately $10 \mathrm{kWh} / \mathrm{kg} \mathrm{Al}$ (versus over $13 \mathrm{kWh} / \mathrm{kg}$ Al for Hall-Heroult), capital costs as low as $\$ 1250$ per MTY (versus 4,000 per MTY for Hall-Heroult), operating cost reductions of over $10 \%$, and up to $37 \%$ reduction in $\mathrm{CO}_{2}$ emissions for fossil-fuel power plants. Realization of these benefits would be critical to sustaining the US aluminum industries position as a global leader in primary aluminum production. One very attractive incentive for ARP is its perceived ability to cost effectively produce metal over a range of smelter sizes, not feasible for Hall-Heroult plants which must be large, 240,000 TPY or more, to be economical. Lower capacity stand alone carbothermic smelters could be utilized to supply molten metal at fabrication facilities similar to the mini-mill concept employed by the steel industry.

The accomplishments of the project are listed:

- The system thermo-chemistry was defined for the Advanced Reactor Process flow diagram.

- An operating diagram was developed based on available thermodynamics for the $\mathrm{Al}_{2} \mathrm{O}_{3}-\mathrm{Al}_{4} \mathrm{C}_{3}$ system.

- Correlations for slag and metal alloy viscosities versus temperature and composition were predicted from developed mathematical expressions.

- Stage 1 was demonstrated at the $1 \mathrm{MW}$ scale.

- Stage 2 critical components were demonstrated in a $500 \mathrm{~kW}$ module.

- The fundamentals of vapor recovery were experimentally determined, including reaction mechanisms and $\mathrm{Al}$ species vapor pressures.

- The detailed design and installation of an advanced Stage 1 system was completed, including a vapor recovery reactor.

- The feasibility of efficient $\mathrm{Al}-\mathrm{C}$ separation was demonstrated.

- Capital and operating cost estimates for the process were updated.

- Computer models were developed for the vapor recovery system and are in progress for Stage 1, Stage 2 and the total process.

- A number of papers were presented and published in Light Metals and other journals and/or conference proceedings. 
- $\quad$ Five US patents have been awarded; 3 patent applications are in process of being reviewed by the US Patent Office.

Based on these accomplishments it was concluded that (1) the thermodynamics of the process are valid; (2) the designs of the Stage 1 and Stage 2 reactor components successfully address the identified technical hurdles related to the pre-reduction and reduction process steps; (3) efficient decarbonization of the Al-C alloy product is feasible; (4) fundamentally, the vapor recovery process concepts are valid; (5) the process economics are favorable compared to the Hall-Heroult process for production of commercial grade $\mathrm{Al}$; and (6) that the program should continue with emphasis on the engineering of the vapor recovery system, followed by the implementation of a $3 \mathrm{MW}$ totally integrated reactor system to demonstrate all steps of the process and to develop additional design data for a large scale pilot reactor system.

It is recommended that the program be continued through the $3 \mathrm{MW}$ integrated reactor evaluation. Based on the results of test campaigns with the integrated reactor, plus a further update on process cost estimates, the next phase of study would be the design and implementation of a large scale pilot reactor. Successful evaluation at the pilot scale would enable the design and implementation of one or more commercial plants sized to meet specific business opportunities. 


\section{INTRODUCTION}

The Aluminum Carbothermic Technology project addresses the Aluminum Industry Technology Roadmap goal of making the U.S. aluminum industry more competitive in world markets. Alcoa's carbothermic process, the Advanced Reactor Process, is projected to reduce capital and operating costs, reduce process energy consumption, and reduce $\mathrm{CO}_{2}$ emissions for smelting. The process is expected to attain an energy rate on the order of $10 \mathrm{kWH} / \mathrm{kg}$ of $\mathrm{Al}$ which is about $25 \%$ lower than the benchmark Hall-Heroult rate of $13.25 \mathrm{kWH} / \mathrm{kg}$.

The carbothermic Advanced Reactor Process is a multi-stage system in which a molten slag bath containing alumina and carbon is reacted to produce aluminum carbide in a low temperature stage. The resulting alumina - aluminum carbide slag then flows into a high temperature stage where the aluminum carbide is reacted with the alumina to produce aluminum metal. The aluminum is less dense than the slag and accumulates as a layer floating on the slag. The low temperature and high temperature stages are located in a common reaction vessel and are separated by an underflow partition wall. The high temperature stage has an outlet for continuously tapping molten aluminum. Additional carbon material is supplied to the high temperature stage to satisfy the reaction stoichiometry

Energy required for the low temperature stage melting and pre-reduction is supplied by high intensity slag resistance heating using vertical carbonaceous electrodes submerged in the molten slag. Similarly, energy to the high temperature stage is high intensity slag resistance heating via a plurality of pairs of horizontally arranged electrodes through the sidewall of the reactor into the slag phase and below the metal phase.

Each reactor stage could have an off-gas reactor attached to capture the energy and aluminum values from volatile aluminum and aluminum sub-oxide leaving the hot reaction zones. These are referred to as vapor recovery reactors, or VRR's. In effect, the aluminum species are reacted with carbon to produce aluminum carbide that is recycled to the high temperature stage to satisfy the carbon stoichiometry for the reduction step.

The tapped molten aluminum product contains some amount of carbon as aluminum carbide. A metal-carbide separation is attained by cooling the mix to precipitate the carbide, followed by degassing prior to casting into ingots or using the molten aluminum as a feed to some other process. The carbide is an additional carbon source for recycle to the high temperature stage of the reactor.

The development program has been focused on empirical R\&D whereby each stage of the Advanced Reactor Process was independently evaluated in modular components ranging in scale from bench $(60-100 \mathrm{~kW}$ furnaces) to laboratory (up to $1500 \mathrm{~kW})$. This includes reactor Stages 1 and 2, vapor recovery and metal product decarbonization. The program was aimed at solving identified engineering problems that were experienced by others in previous research attempts. These problems included efficient delivery of energy to attain the high temperatures required to effect reduction of alumina by carbon to produce 
aluminum; materials of construction issues; excessive losses of aluminum values and sensible heat due to volatilization; high electrode carbon consumption; and efficient separation of aluminum from carbon to recover commercial grade metal. An additional requirement was that potential solutions had to be economically viable.

Successful production of commercial grade aluminum would result in a generic metal that can be used in any of the typical applications and markets, including aerospace, automotive, packaging and building. If Carbothermic Aluminum Technology is successful, and if it replaced the existing process, the annual energy savings for the U.S. primary aluminum industry would be on the order of 1,500 MWe based on 2003 domestic production. The long term plan for commercialization includes completion of the process feasibility in a $3 \mathrm{MW}$ integrated reactor system, scale up to a pilot unit and design of a commercial facility in the next 6 to 8 years. 


\section{BACKGROUND}

The objectives of this project are to demonstrate the technical and economic feasibility of the Advanced Reactor Process. Technical feasibility will be demonstrated through completion of a number of tasks that include fundamental experiments related to the vapor recovery system; energy and mass calculations to assess impact of various flow schemes for the process; development of computer models for the reactor stages, the vapor recovery system and the total process; physical modeling to study dynamic parameters for the reactor stages; design, fabrication, assembly, installation and operation of process units both in modular form and as integrated systems, to include reactor Stages 1 and 2, the vapor recovery systems and the product decarbonization unit. Economic feasibility will be accomplished through capital and operating cost estimates continuously upgraded as new information is developed about the process.

Over the last 50 years, many previous attempts were made to develop a successful carbothermic approach to aluminum production. Reynolds worked on an electric arc process from 1971 through 1984. They designed, built and operated small furnaces, 100 to $200 \mathrm{~kW}$ size. Their process was a batch system that contained 3 phases of sequential operation: slag pool building using submerged electrodes; reduction and metal making using an open arc mode; and decarbonization of the product metal by alumina extraction of the aluminum carbide. Reynolds identified several major technical hurdles, including (1) an effective power delivery system that would supply heat at greater than $2100^{\circ} \mathrm{C}$ while avoiding short circuiting and minimizing vaporization of aluminum; (2) efficient charge column operation to recover volatiles; and (3) effective decarbonization of the metal product. Reynolds terminated their efforts due to the perceived costs for scale-up R\&D.

Pechiney conducted research on electric arc furnace carbothermic reduction from 1955 to 1967. Through 1960, they operated a variety of furnaces ranging from $150 \mathrm{~kW}$ single phase to $2.7 \mathrm{MW}$ three phase and produced carbide saturated metal containing $60 \%$ aluminum. From 1960 to 1967, Pechiney ran a single phase furnace at up to $6 \mathrm{MW}$, producing 300 tons of carbide saturated metal; and a $2 \mathrm{MW}$, three phase unit that made 540 tons of $70-80 \% \mathrm{Al}$. Their carbothermic processes turned out to be cost prohibitive due to high consumptions of alumina and carbon, high vaporization losses and high energy usage $(18.75 \mathrm{kWH} / \mathrm{kg})$.

Alcan acquired information from Pechiney and attempted to solve the problems that Pechiney had experienced. Alcan did employ a two stage concept to reduce the volatility issues. Two reaction chambers were used, requiring transfer and recycle of molten slag through resistance heated pipes. However, their design was difficult to implement and eventually they stopped their program in the early 1980's.

Alcoa tried to develop a blast furnace type carbothermic reactor from 1977 to 1982 for the production of Al-Si alloy. The reactor was similar to an iron making unit, with heat supplied by oxygen combustion of coke. This concept also failed. Volatile species flowing up through the downward moving charge condensed in the colder regions and plugged the bed. By the end of the Alcoa program, we were running a bench scale $(100 \mathrm{~kW})$ 
submerged arc furnace which did make Al-Si alloy. In 1999, at the start of our latest effort on carbothermic production of Al, Alcoa hired Mintek to conduct electric furnace tests to evaluate the effects of arc mode on reactor performance. Using a $200 \mathrm{~kW}$ unit, Mintek demonstrated that an open arc would not work well due to high volatile generation. Their results confirmed that a submerged arc process was critical to successful production and recovery of $\mathrm{Al}$.

In 1999 at an Alcoa sponsored 3-day workshop on carbothermic approaches to Al, Elkem proposed the basic concept that has become known as the Advanced Reactor Process. As described, the process utilizes slag resistance heating through submerged arc operation. Elkem was an ideal partner to jointly develop the new process since they have a long history of expertise in high temperature metallurgical processes, much of which is founded in electric furnace systems.

Combined with Alcoa's know-how in aluminum smelting and purification, the AlcoaElkem team is very highly qualified to address the technical challenges posed by successful implementation of carbothermic reduction. Elkem employs their best design and process engineers located at both Oslo and at their R\&D center in Kristiansand, Norway. Elkem also provides an excellent facility for the development work, including high bay space, electric power supplies, machine shops and analytical laboratories. They can operate electric furnaces ranging from $60 \mathrm{~kW}$ to over $3 \mathrm{MW}$.

Alcoa provides experienced engineers and technologists plus excellent facilities at the Alcoa Technical Center (ATC). Most of the fundamental research is being conducted at ATC as well as the development of decarbonization concepts that utilize Alcoa technology for purifying Al. In addition, Alcoa has contracted key consultants expert in high temperature metallurgy and in computer modeling. Carnegie Mellon University (CMU) is also under contract to work on advanced computer models of the process steps. 


\section{TECHNICAL PROGRESS}

Work done under this contract can be categorized in the following subject:

Fundamental Research;

Computer Modeling;

Reactor Development;

Decarbonization Development;

Economic Analysis.

\section{Fundamental Research}

\section{Thermodynamic Background}

The overall reaction for carbothermic aluminum production can be written

$$
\begin{aligned}
& \mathrm{Al}_{2} \mathrm{O}_{3}+3 \mathrm{C}=2 \mathrm{Al}+3 \mathrm{CO} \\
& \begin{array}{lllll}
25 & 25 & 2000 & 600 & { }^{\circ} \mathrm{C}
\end{array}
\end{aligned}
$$

The temperatures of the products are reasonable estimates for the process. According to thermochemical data, the energy consumption for this reaction is $7.9 \mathrm{kWh} / \mathrm{kg} \mathrm{Al}$. Carbothermic processes often have an energy efficiency around 80 percent, and the expected energy consumption for very good operation then becomes $10 \mathrm{kWh} / \mathrm{kg}$ Al. The process can also get energy credit for the $\mathrm{CO}$ that can be used as fuel to produce power and/or as preheat for charge materials.

When $\mathrm{Al}_{2} \mathrm{O}_{3}$ and $\mathrm{C}$ is heated at atmospheric pressure, a rather complex product is formed. Much of the process chemistry can be understood from the phase diagram $\mathrm{Al}_{4} \mathrm{C}_{3}-\mathrm{Al}_{2} \mathrm{O}_{3}$, which is shown in Figure $1^{(1)}$. The species $\mathrm{Al}_{2} \mathrm{O}_{3}$ and $\mathrm{Al}_{4} \mathrm{C}_{3}$ can occur as separate phases, or they can combine to make a liquid $\mathrm{Al}_{2} \mathrm{O}_{3}-\mathrm{Al}_{4} \mathrm{C}_{3}$ slag. With fixed pressure the equilibrium is completely determined when the system has either three condensed phases or two condensed phases and one of them is slag with a given composition. Two completely determined combinations are possible: $\mathrm{Al}_{2} \mathrm{O}_{3}-\mathrm{C}-\mathrm{Al}_{4} \mathrm{C}_{3}$ and $\mathrm{Al}_{2} \mathrm{O}_{3}-\mathrm{Al}_{4} \mathrm{C}_{3}-\mathrm{Al}$. The species $\mathrm{Al}_{4} \mathrm{C}_{3}$ is stable only up to $2150^{\circ} \mathrm{C}$; above it decomposes to $\mathrm{Al}$ and $\mathrm{C}$. The $\mathrm{Al}$ phase always contains some $\mathrm{C}$, and it can be considered as an alloy Al-C. 


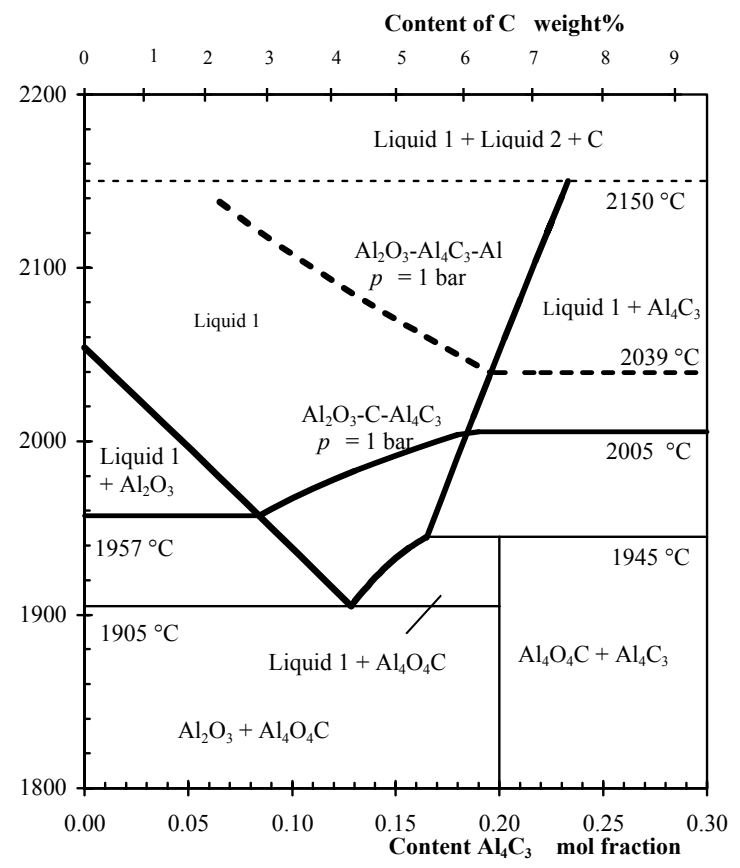

\section{Figure 1: The Pseudobinary Phase Diagram $\mathrm{Al}_{4} \mathrm{C}_{3}-\mathrm{Al}_{2} \mathrm{O}_{3}$ with Equilibrium Temperatures for the Main Phase Combinations.}

The high electrical conductivity of the melt $\mathrm{Al}_{4} \mathrm{C}_{3}-\mathrm{Al}_{2} \mathrm{O}_{3}$ indicates that it is ionic. Motzfeldt et al. assumed that it consists of the three monovalent ions $\mathrm{AlO}^{-}, \mathrm{AlO}_{2}{ }^{-}$and $\mathrm{AlC}^{-}$that form an ideal mixture according to Temkin. From this assumption they could reproduce the pseudobinary diagram $\mathrm{Al}_{4} \mathrm{C}_{3}-\mathrm{Al}_{2} \mathrm{O}_{3}$ fairly accurately. This fact does not prove that the suggested melt model is correct, but it shows that the experimental facts can be interpreted by a very simple melt model. The reactions in the system can be expressed as ionic reactions. For example, the dissolution of $\mathrm{Al}_{4} \mathrm{C}_{3}$ in the slag phase can be described by

$$
\mathrm{Al}_{4} \mathrm{C}_{3}+\mathrm{Al}_{2} \mathrm{O}_{2}^{-}=2 \mathrm{AlO}^{-}+3 \mathrm{AlC}^{-}
$$

Other reactions in the systems can be interpreted similarly.

An alternative diagram, Figure 2, was developed by Alcoa based on the thermodynamics for the $\mathrm{Al}_{2} \mathrm{O}_{3}-\mathrm{Al}_{4} \mathrm{C}_{3}$ system reported by Qui and Metselaar ${ }^{(2)}$. In addition to the phases, the concentration of $\mathrm{Al}_{4} \mathrm{C}_{3}$ in the alloy product and the instantaneous percent of $\mathrm{Al}$ species vaporized are shown. The fact that the two thermodynamic systems are not in total agreement is a measure of the uncertainty of the thermochemical data. 


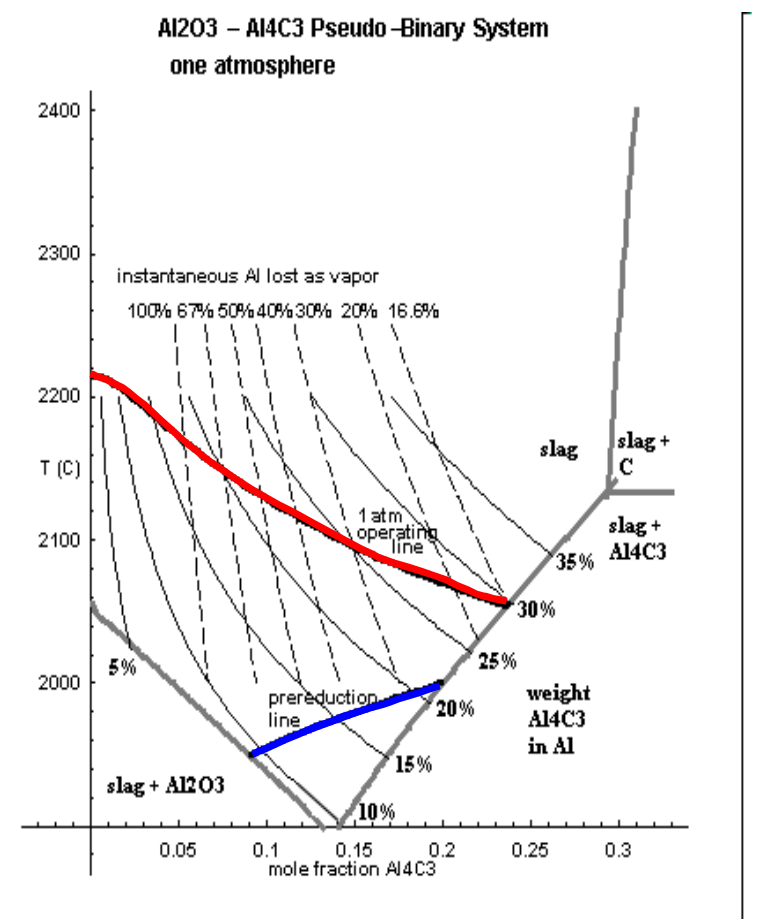

Figure 2: Alcoa Operating Diagram of the Al-C-O System.

The thermodynamic condition for reaction with a considerable rate is that the overall equilibrium vapor pressure of the reaction is larger than the ambient pressure, which is assumed to be 1 bar. The system has three gaseous species with significant amounts: CO, $\mathrm{Al}_{2} \mathrm{O}$ and $\mathrm{Al}$. The condition for reaction is therefore

$$
\mathrm{p}^{\prime}{ }_{\mathrm{CO}}+\mathrm{p}^{\prime}{ }_{\mathrm{Al} 2 \mathrm{O}}+\mathrm{p}^{\prime} \mathrm{Al} \geq 1 \text { atmosphere }
$$

where $\mathrm{p}^{\prime} \mathrm{X}$ is the equilibrium pressure of the gas species $\mathrm{X}$. Here the equal sign stands for the limiting equilibrium situation. The temperatures giving $\sum \mathrm{p}^{\prime}=1$ atmosphere for the two combinations $\mathrm{Al}_{2} \mathrm{O}_{3}-\mathrm{C}-\mathrm{Al}_{4} \mathrm{C}_{3}$ and $\mathrm{Al}_{2} \mathrm{O}_{3}-\mathrm{Al}_{4} \mathrm{C}_{3}-\mathrm{Al}$ are shown in Figure 1 as functions of the slag composition, and the corresponding equilibrium contents of $\mathrm{Al}_{2} \mathrm{O}$ and $\mathrm{Al}$ are shown in Figure $3 \mathrm{a}$ and $3 \mathrm{~b}$. 


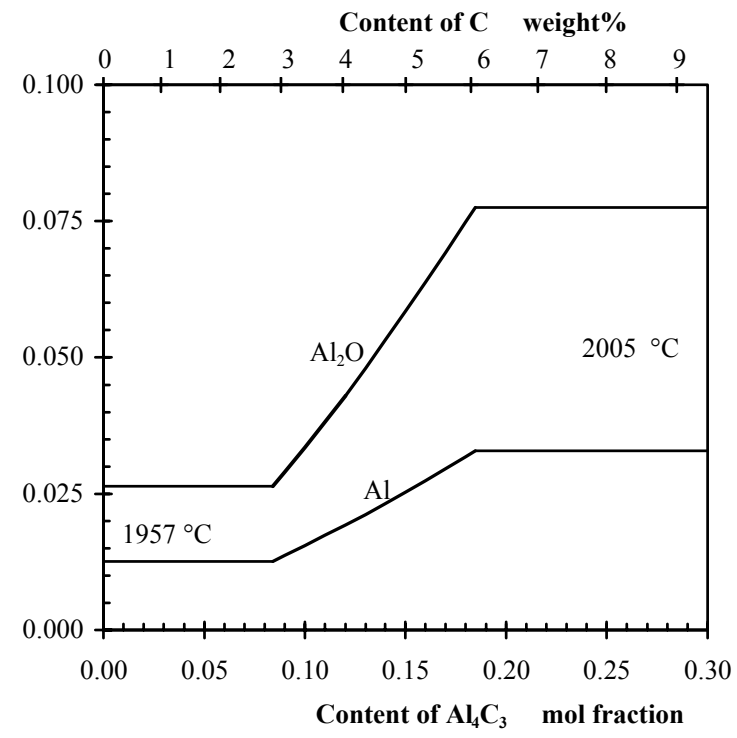

Figure 3a: Gas in Equilibrium with $\mathrm{Al}_{2} \mathrm{O}_{3}-\mathrm{C}-\mathrm{Al}_{4} \mathrm{C}_{3}$.

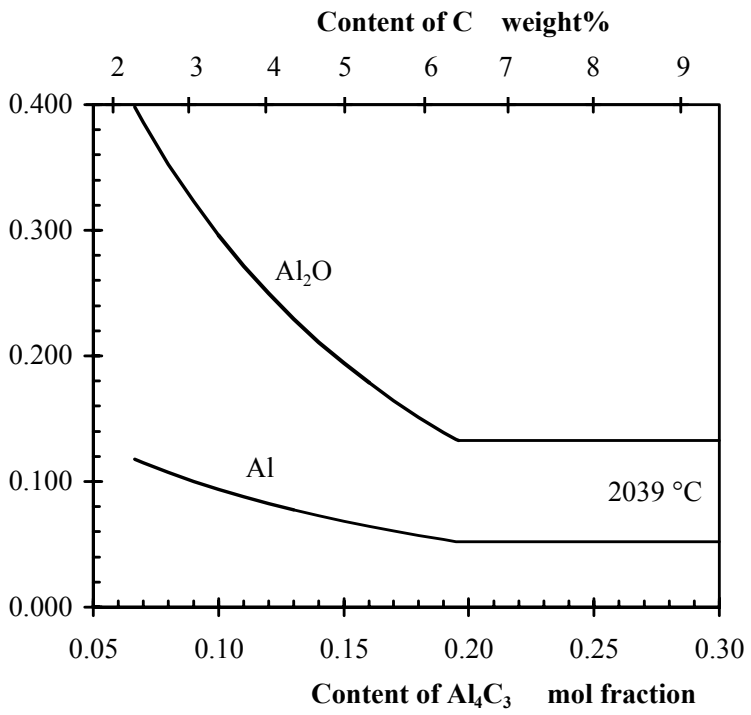

Figure 3b: Gas in Equilibrium with $\mathrm{Al}_{2} \mathrm{O}_{3}-\mathrm{Al}_{4} \mathbf{c}_{3}-\mathrm{Al}$.

In a reactor at equilibrium temperature the reaction rate is very low, but it increases with rising temperature until a steady state is reached where the energy addition is equal to the heat consumption and loss to the surroundings. In steady state the reactor temperature giving $\sum p^{\prime}=1$ is a lower limit, and the real temperature is determined by the electrical load and the kinetics of the reactions. The reaction system is not in equilibrium, and the composition of the gas is determined by the relative rate of the partial reactions. The equilibrium of the systems $\mathrm{Al}_{2} \mathrm{O}_{3}-\mathrm{C}-\mathrm{Al}_{4} \mathrm{C}_{3}$ and $\mathrm{Al}_{2} \mathrm{O}_{3}-\mathrm{Al}_{4} \mathrm{C}_{3}-\mathrm{Al}$ gives a first approximation for estimates of the gas composition, and equilibrium calculations for tentatively selected favored reactions can be used as a means for better estimates. 
For aluminum production the charge will be $\mathrm{Al}_{2} \mathrm{O}_{3}+\approx 3 \mathrm{C}$. If this mixture is heated to an appropriate temperature, it will react until the $\mathrm{C}$ is consumed and $\mathrm{Al}_{4} \mathrm{C}_{3}$ dissolved in the slag phase is the only $\mathrm{C}$-containing species:

$$
2 \mathrm{Al}_{2} \mathrm{O}_{3}+9 \mathrm{C}=\mathrm{Al}_{4} \mathrm{C}_{3}+6 \mathrm{CO}
$$

This is Stage 1 of the reaction, where free $\mathrm{C}$ is consumed. If the mixture is heated further, $\mathrm{Al}_{4} \mathrm{C}_{3}$ and $\mathrm{Al}_{2} \mathrm{O}_{3}$ react until one of them is consumed:

$$
\mathrm{Al}_{4} \mathrm{C}_{3}+\mathrm{Al}_{2} \mathrm{O}_{3}=6 \mathrm{Al}+3 \mathrm{CO}
$$

This is Stage 2 of the reaction. This division into stages is appropriate for sequential heating of a mixture. In both stages the gas from the reaction will contain $\mathrm{Al}_{2} \mathrm{O}$ and $\mathrm{Al}$. In this process picture, the alloy is produced by reaction between $\mathrm{Al}_{2} \mathrm{O}_{3}$ and $\mathrm{Al}_{4} \mathrm{C}_{3}$. If the charge to the alloy production reactor also contains an even flow of free $\mathrm{C}$ and sufficient energy is added to keep the temperature high enough for alloy production, the Stages 1 and 2 will run simultaneously. The Stage 1 of the free $\mathrm{C}$ reaction corresponds to an extra addition of $\mathrm{CO}$, and this $\mathrm{CO}$ will have the same content of Al-containing species as the gas from alloy production. With free $\mathrm{C}$ in the charge, more of these species will be transported to the vapor recovery reactor per unit alloy produced than for a charge where all of the $\mathrm{C}$ is added as $\mathrm{Al}_{4} \mathrm{C}_{3}$. However, as long as there is enough free $\mathrm{C}$ in the recovery charge, the Al-containing species can be captured and the Al recovery for the overall process can be high. The process is self-stabilizing. If for some reason the amount of free $\mathrm{C}$ becomes extraordinarily large, more Al-containing gas species will flow to the vapor recovery reactor where it consumes more free $\mathrm{C}$. Then less free $\mathrm{C}$ is left in the charge going to the alloy production reactor. This mechanism can give a high recovery as long as the amount of $\mathrm{C}$ available for the vapor recovery reactor is large enough. With a very high content of Al-containing species in the gas, the charge will not contain enough $\mathrm{C}$ for complete capture. This may set a lower limit for the acceptable $\mathrm{Al}_{4} \mathrm{C}_{3}$ content of the slag.

In the ACT-ARP concept, the necessary reactions are carried out in a combination of reactors. Figure 4 shows the material flows between them. 


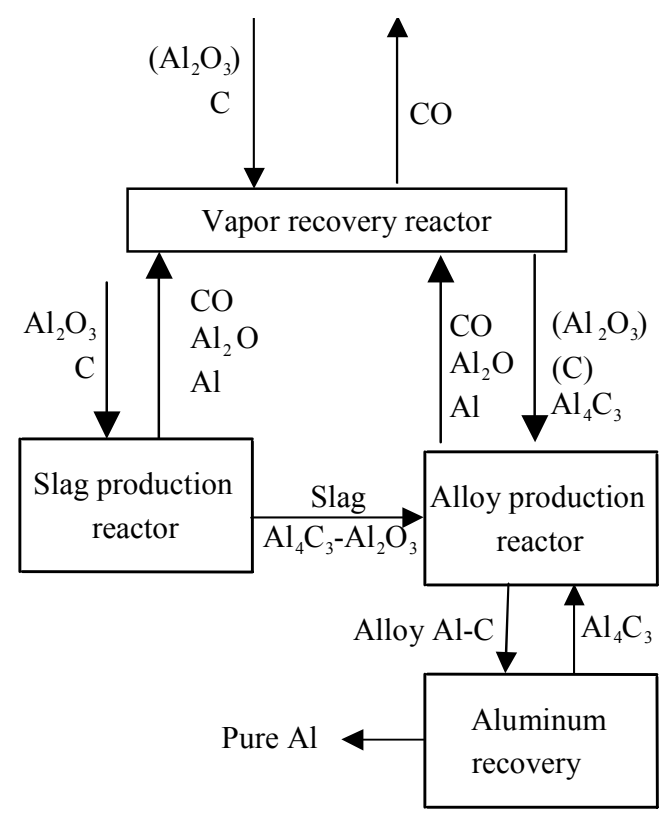

\section{Figure 4: Flow Chart of the ACT-ARP Concept for Carbothermic Aluminum Production.}

The reaction in the alloy production reactor gives off hot gas with a high content of $\mathrm{Al}_{2} \mathrm{O}$ and Al. The process economics requires that the aluminum and the energy are recovered, and the vapor recovery reactor is added for that purpose. The recovery reactor charge is primarily $\mathrm{C}$ but could include some amount of $\mathrm{Al}_{2} \mathrm{O}_{3}$ in certain circumstances. The charge enters the recovery reactor at the ambient temperature, which for simplicity is set equal to $25^{\circ} \mathrm{C}$. The recovery reactor can be visualized as a shaft where the charge passes through countercurrent to the gas. Since the Al-producing reaction needs temperature in excess of the equilibrium temperature, the gas from the reaction can heat the materials in the recovery reactor to a temperature above the temperature of alloy production. Then the only condensed species that are stable at equilibrium at this temperature are $\mathrm{Al}_{4} \mathrm{C}_{3}$ and $\mathrm{Al}$, or $\mathrm{Al}_{4} \mathrm{C}_{3}$ and $\mathrm{C}$ if there is a surplus of $\mathrm{C}$ in the recovery reactor. Then the product from the recovery reactor must be either $\mathrm{Al}_{4} \mathrm{C}_{3}-\mathrm{Al}$ or $\mathrm{Al}_{4} \mathrm{C}_{3}-\mathrm{C}$. However, if the recovery charge contains $\mathrm{Al}_{2} \mathrm{O}_{3}$, some of the reactions in the vapor recovery reactor are endothermic, and additional heat may be necessary to complete the reaction.

In a countercurrent reactor, the exit gas can be cooled to sufficiently low temperatures such that the content of the Al-containing species is practically zero. Thus the process can in principle emit pure CO. The alloy from Stage 2 flows to the aluminum recovery unit where it will undergo further treatment to remove $\mathrm{C}$ to commercial grade $\mathrm{Al}$ levels.

\section{Slag and Metal Viscosities}

Professor Sridhar Seetharaman from Carnegie Mellon was contracted to provide estimates of slag and metal viscosities as a function of compositions for a range of temperatures. 
Professor Seetharaman developed mathematical expressions for the viscosities of $\mathrm{Al}_{2} \mathrm{O}_{3}-\mathrm{Al}_{4} \mathrm{C}_{3}$ slag compositions containing up to $0.4 \mathrm{~mol}$ fraction of $\mathrm{Al}_{4} \mathrm{C}_{3}$ over a temperature range of $1950^{\circ} \mathrm{C}$ to $2150^{\circ} \mathrm{C}$ using a model developed by Roscoe for handling two phase regions such as solids suspended in liquid slag. Predicted viscosities were on the order of $0.27 \mathrm{~Pa} . \mathrm{s}$ at $0.4 \mathrm{~mol}$ fraction $\mathrm{Al}_{4} \mathrm{C}_{3}$. The correlations are shown in Figure 5.

Professor Seetharaman also developed an expression for the viscosity of Al- $\mathrm{C}$ over a range of $\mathrm{C}$ compositions up to 45 weight per cent for a temperature range of $1850^{\circ} \mathrm{C}$ to $2250^{\circ} \mathrm{C}$. For example, the viscosity was $0.0028 \mathrm{~Pa} . \mathrm{s}$ at $2025^{\circ} \mathrm{C}$ and $20 \% \mathrm{C}$. Correlations are shown in Figure 6.

The procedures for developing the fundamental expressions were complex. Professor Seetharaman has written a technical paper on the subject ${ }^{(3)}$. The viscosity values determined by Professor Seetharaman will be used in dynamic computer models under development.

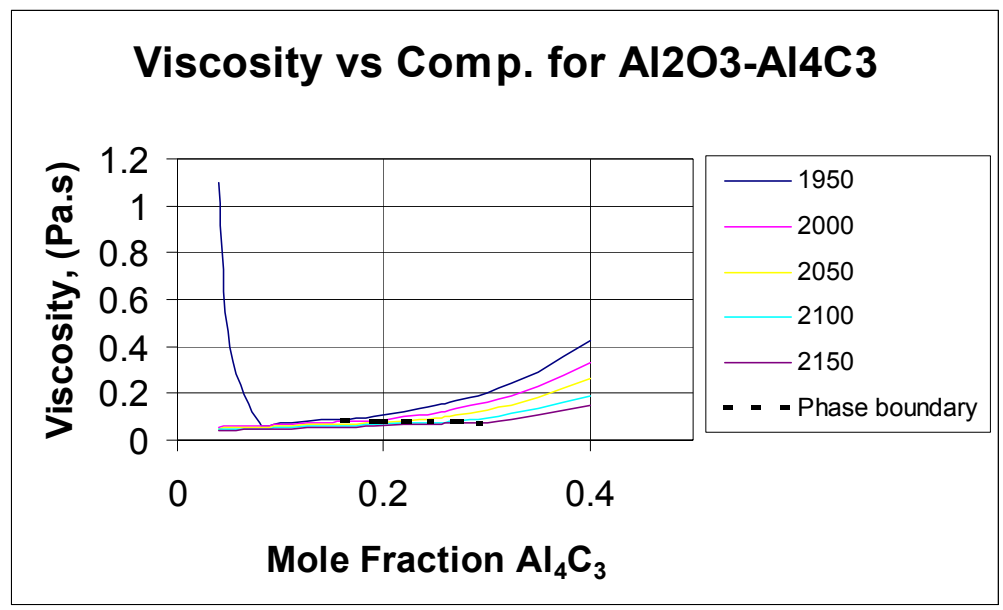

Figure 5: Viscosity vs. Composition for $\mathrm{Al}_{2} \mathrm{O}_{3}-\mathrm{Al}_{4} \mathrm{C}_{3}$.

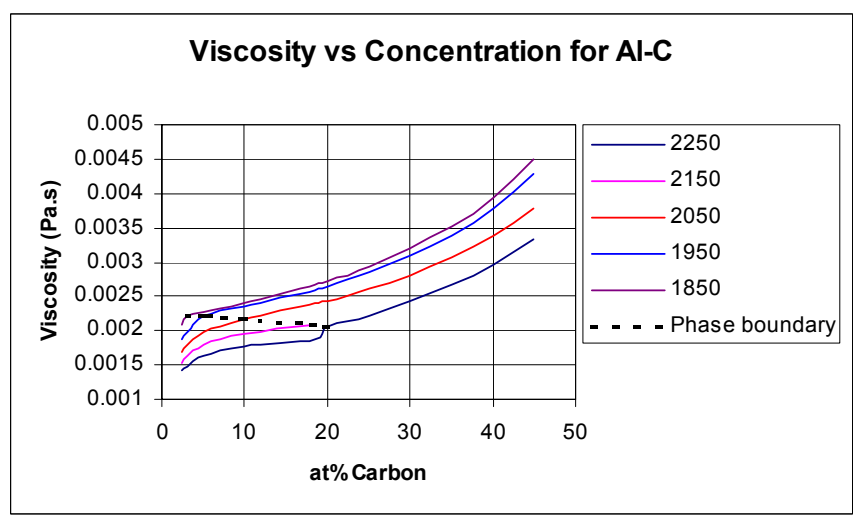

Figure 6: Viscosity vs. Concentration for Al-C. 


\section{Mechanism and Rate of Reaction of $\mathrm{Al}_{2} \mathrm{O}, \mathrm{Al}$ and $\mathrm{CO}$ Vapors with Carbon}

Alcoa and Carnegie Mellon University collaborated on experimentally determining the mechanism and rate of reactions of gas containing $\mathrm{Al}$ and $\mathrm{Al}_{2} \mathrm{O}$ with various types of carbon to form $\mathrm{Al}_{4} \mathrm{C}_{3}{ }^{(4)}$. This is the preferred method for recovering the aluminum values in the reactor off gases, with the carbide being recycled to Stage 2 of the reactor to satisfy the stoichiometry of the reduction step. The $\mathrm{Al}-\mathrm{Al}_{2} \mathrm{O}-\mathrm{CO}$ gas was generated by reacting an $\mathrm{Al}_{2} \mathrm{O}_{3}-\mathrm{Al}_{4} \mathrm{C}_{3}$ melt with carbon at high temperatures $\left(2000^{\circ} \mathrm{C}\right.$ to $\left.2050^{\circ} \mathrm{C}\right)$ in the Alcoa $65 \mathrm{~kW}$ induction heated furnace. The gas was then reacted with carbon at lower temperatures $\left(1900^{\circ} \mathrm{C}\right.$ to $\left.1950^{\circ} \mathrm{C}\right)$. A schematic diagram of the experimental equipment is shown in Figure 7. The melts used to generate the vapors were heated in a graphite crucible $(17.5 \mathrm{~cm}$ ID). About $7 \mathrm{~kg}$ of slag was charged. The temperatures of the melt and at the sample location were measured with a tungsten-rhenium $(5 \% \mathrm{~W}-\mathrm{Re})-(26 \% \mathrm{~W}-\mathrm{Re})$ thermocouple which is capable of measuring temperatures up to $2200^{\circ} \mathrm{C}$. A two color optical pyrometer was also used to measure the temperature. The two temperature measurement techniques agreed within $10^{\circ} \mathrm{C}$. The furnace was continuously flushed with argon to avoid excessive oxidation. The off gas composition was measured by an inline mass spectrometer. The primary species were $\mathrm{CO}, \mathrm{Ar}$ and $\mathrm{N}_{2}$; all of the $\mathrm{Al}$ containing species either reacted or condensed before entering the mass spectrometer.

Several different types of carbon were tested, including wood charcoal, metallurgical coke, petroleum coke and graphite. Prior to reaction, the carbons used were examined in an SEM. Refer to Figures $8 \mathrm{a}$ and $8 \mathrm{~b}$. In addition, the bulk density, porosity and average pore size was measured. Results are shown in Table 1. The carbon samples were in the form of cylinders, about $25 \mathrm{~mm}$ diameter by $25 \mathrm{~mm}$ high. Each carbon sample was attached to a graphite rod.

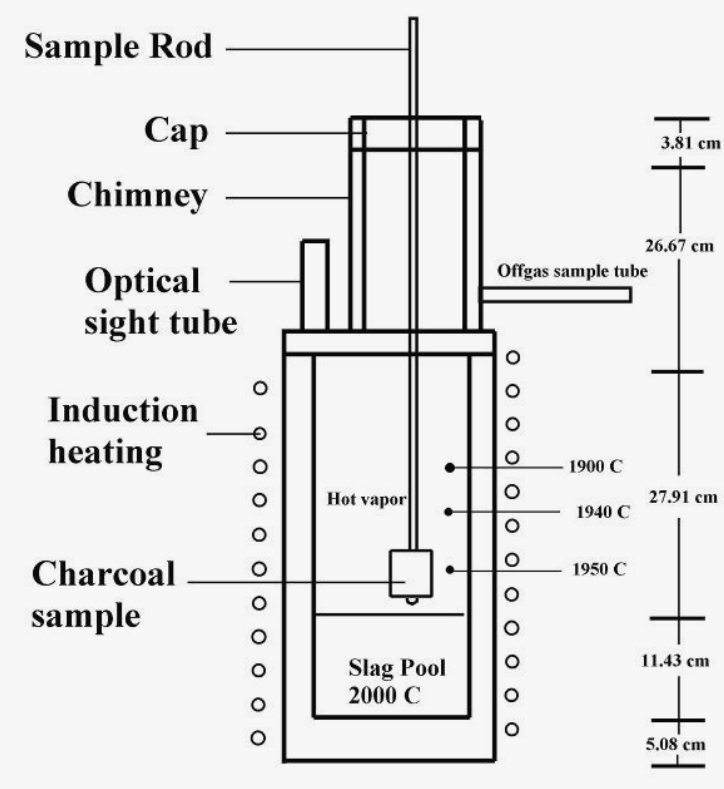

Figure 7: Schematic Diagram of Experimental Equipment. 
Table 1: Properties of the Unreacted Forms of Carbon Tested

\begin{tabular}{|l|c|c|c|c|}
\cline { 2 - 5 } \multicolumn{1}{c|}{} & $\begin{array}{c}\text { Bulk Density } \\
\text { g/ml }\end{array}$ & $\begin{array}{c}\text { Average Pore } \\
\text { Diameter, mm }\end{array}$ & $\begin{array}{c}\text { Porosity \% } \\
\text { A }\end{array}$ & $\begin{array}{c}\text { Porosity \%o } \\
\text { B }\end{array}$ \\
\hline Met. Coke 1 & 1.0378 & 0.0205 & 24.2 & 50.5 \\
\hline Pet Coke & 1.6003 & 0.0302 & 24.7 & 23.8 \\
\hline Met. Coke 2 & 0.919 & 0.0907 & 50.3 & 56.2 \\
\hline Wood Charcoal & 0.5165 & 0.0655 & 61.7 & 75.4 \\
\hline
\end{tabular}

A Open pore Porosity

B Total Porosity

Once the desired temperature was achieved, and the vapors were being generated, the carbon samples were lowered into the upper "chimney" of the unit, reacted for a specified period of time and then withdrawn. The samples were rapidly transferred to a cooling chamber at room temperature which was continuously flushed with argon to avoid excessive oxidation of the reaction products or carbon. The samples were generally mounted and examined in a scanning electron microscope (SEM) and the phases analyzed with EDX. In a few cases the samples were analyzed chemically.

In several experiments the carbon samples were held higher up in the chimney where the temperature was about $1930^{\circ} \mathrm{C}$. At this temperature, a $\left(\mathrm{Al}_{2} \mathrm{O}_{3}-\mathrm{Al}_{4} \mathrm{C}_{3}\right)$ slag was formed. In subsequent experiments, after holding the samples at $1930^{\circ} \mathrm{C}$ for 15 minutes, they were lowered to where the temperature was $1950^{\circ} \mathrm{C}$ and the carbide was formed. These experiments were conducted to determine if the slag formed would inhibit diffusion of the $\mathrm{Al}_{2} \mathrm{O}$ and $\mathrm{Al}$ into the carbon and therefore the formation of the carbide. This is an important concern since in the counter current vapor recovery unit (VRR) the carbon particles will first be at a lower temperature where the slag will form.

As seen in Figure 8a, the wood charcoal has a large uniform porosity. As a result, the wood charcoal reacted the best of all carbon types tested. $\mathrm{Al}_{4} \mathrm{C}_{3}$ formed both on and in the wood charcoal, whereas with pet coke there was some reaction, while with graphite only the condensation reactions occurred at the outer surface of the carbon sample. Figure $8 \mathrm{~b}$ shows the metallurgical coke structure. SEM pictures of the carbide-carbon interface, of the carbide forming in the pores and of slag formation are shown in Figures 9, 10 and 11 for wood charcoal. As seen in Figure 9, the interface between the unreacted carbon and carbide phase is fairly distinct and easy to identify. There is a small region of partially reacted carbon. As shown in Figure 10a, the carbide crystals begin to grow into the porosity of the carbon and when there is primarily $\mathrm{Al}_{4} \mathrm{C}_{3}$ the porosity is greatly reduced, Figure 10b. The liquid slag is dense and most likely slows any further reaction as shown in Figure 11.

In addition to having the highest porosity and the most uniform pore structure, wood charcoal also contains the lowest amount of ash except for graphite, which does not react and is not a practical carbon source. This reduces the potential for contamination of the product metal phase. 


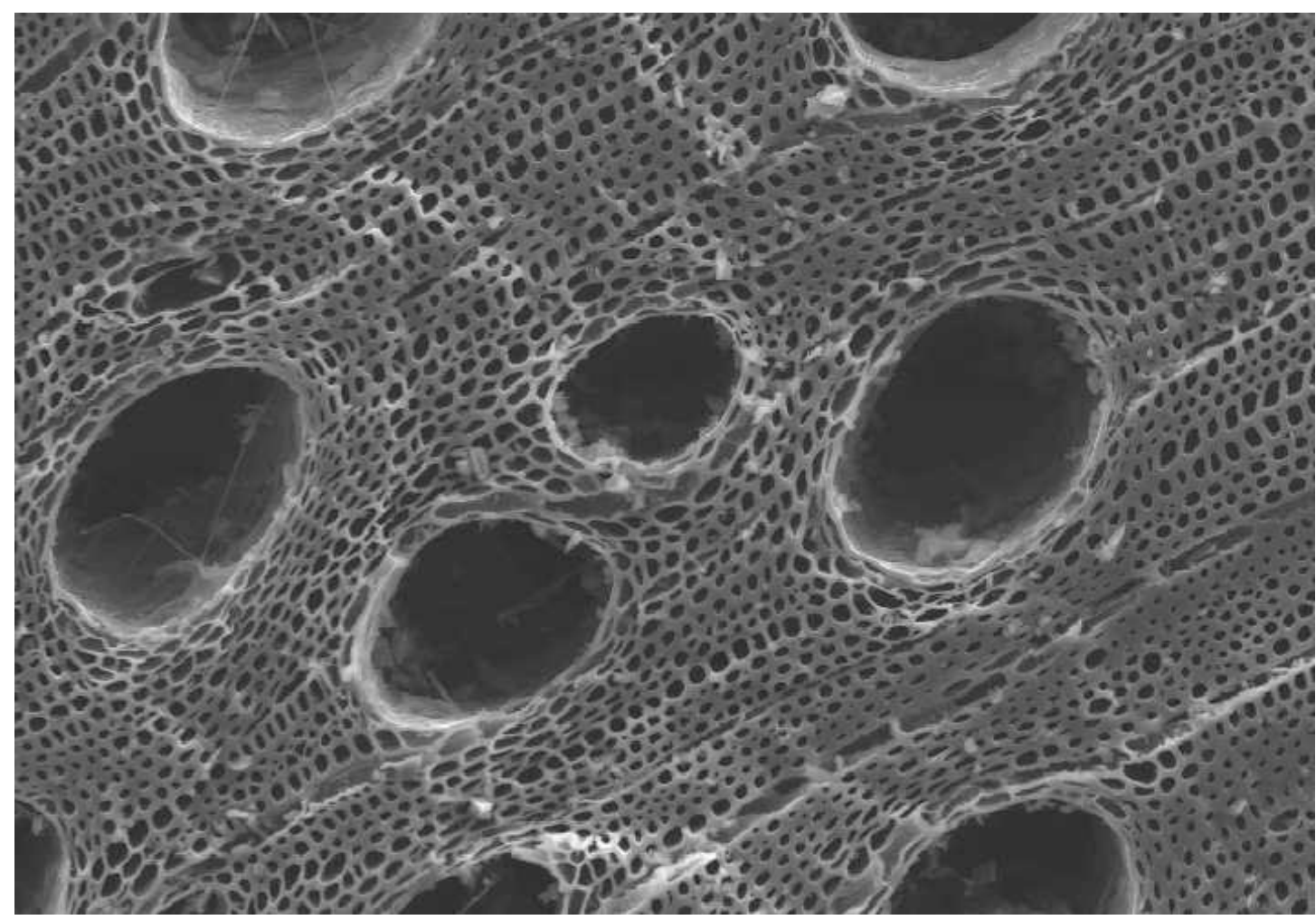

Figure 8a: Wood Charcoal Structure.

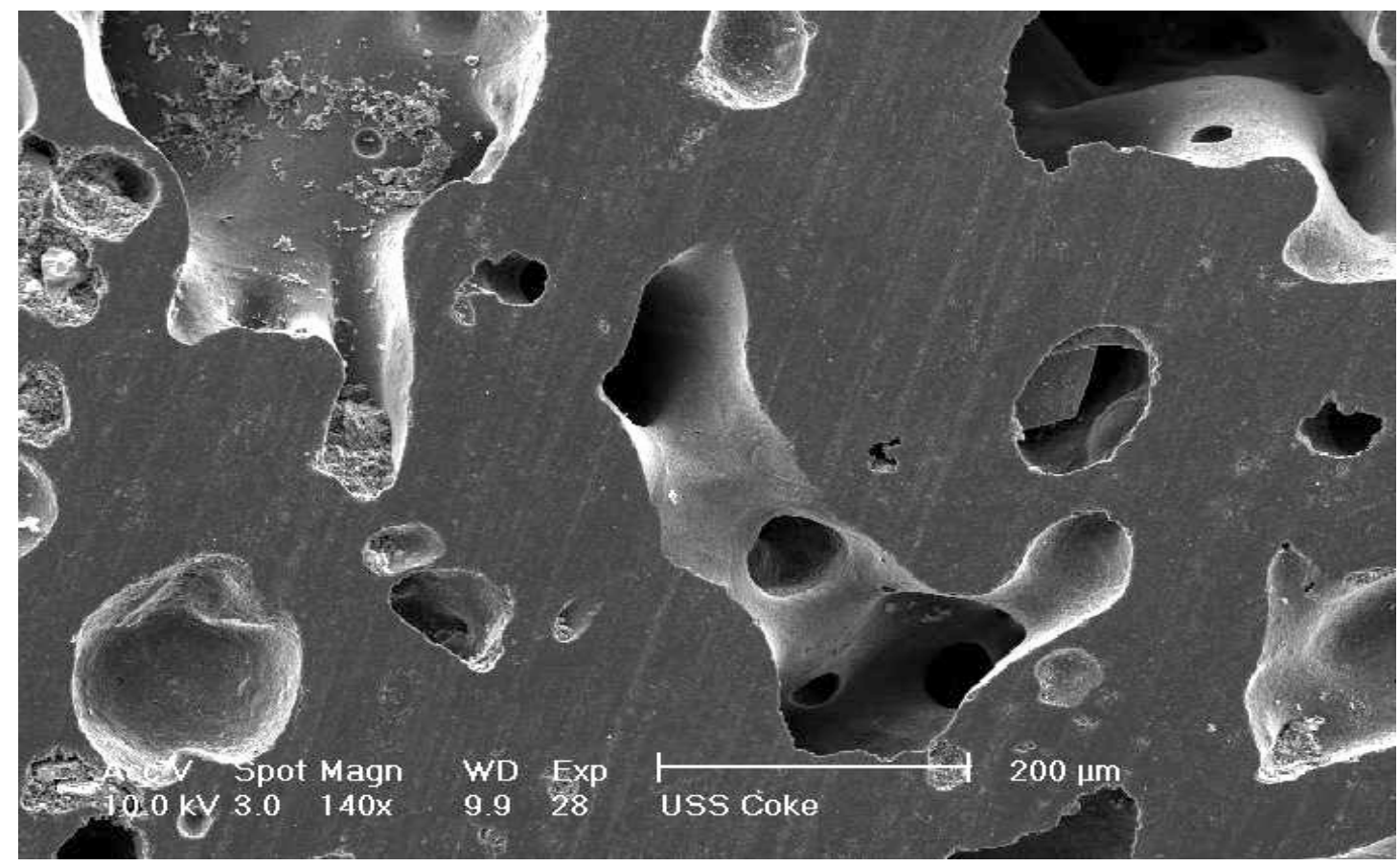

Figure 8b: Metallurgical Coke Structure. 


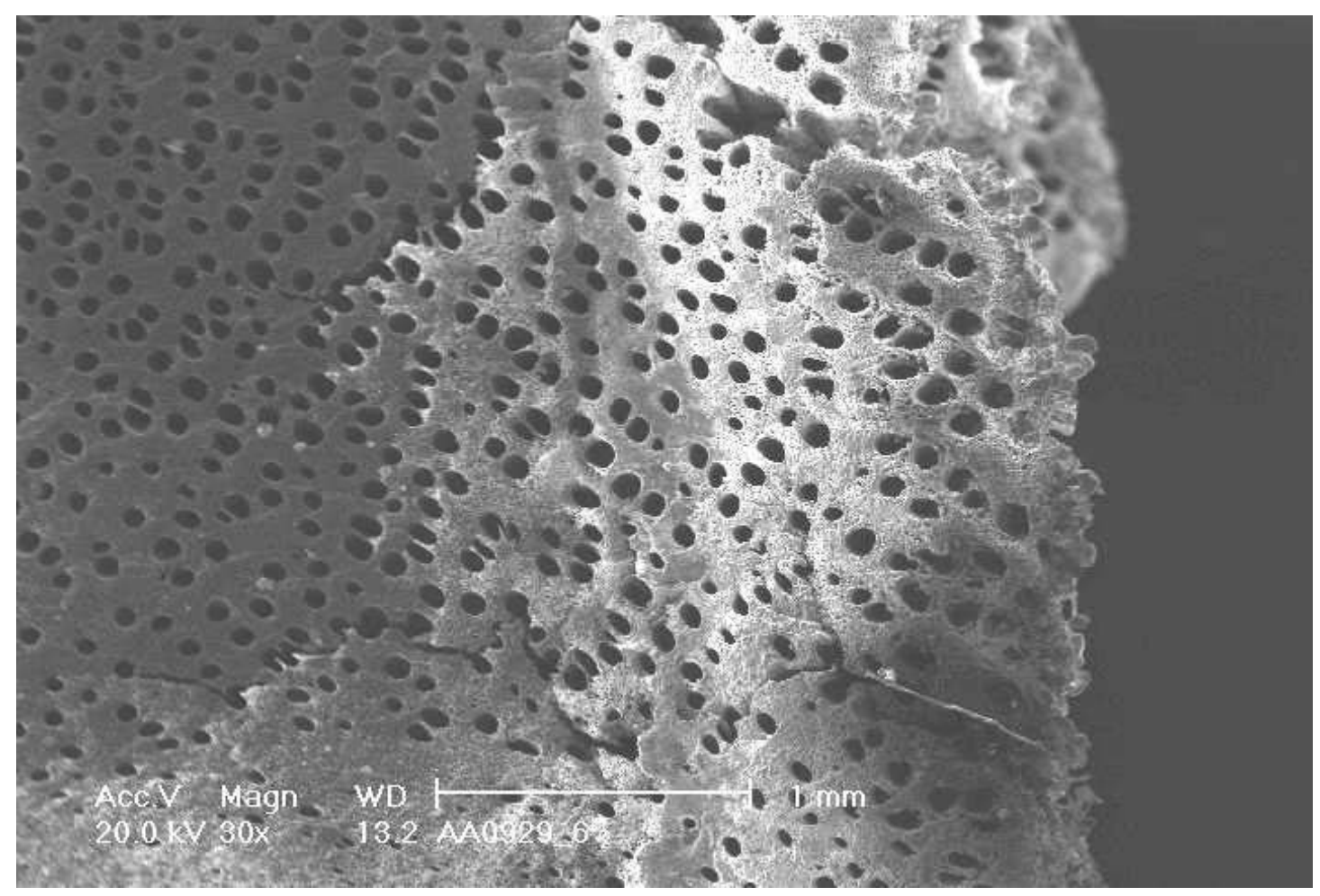

Figure 9: Reacted Wood Charcoal Indicating Carbon-Carbide Interface.

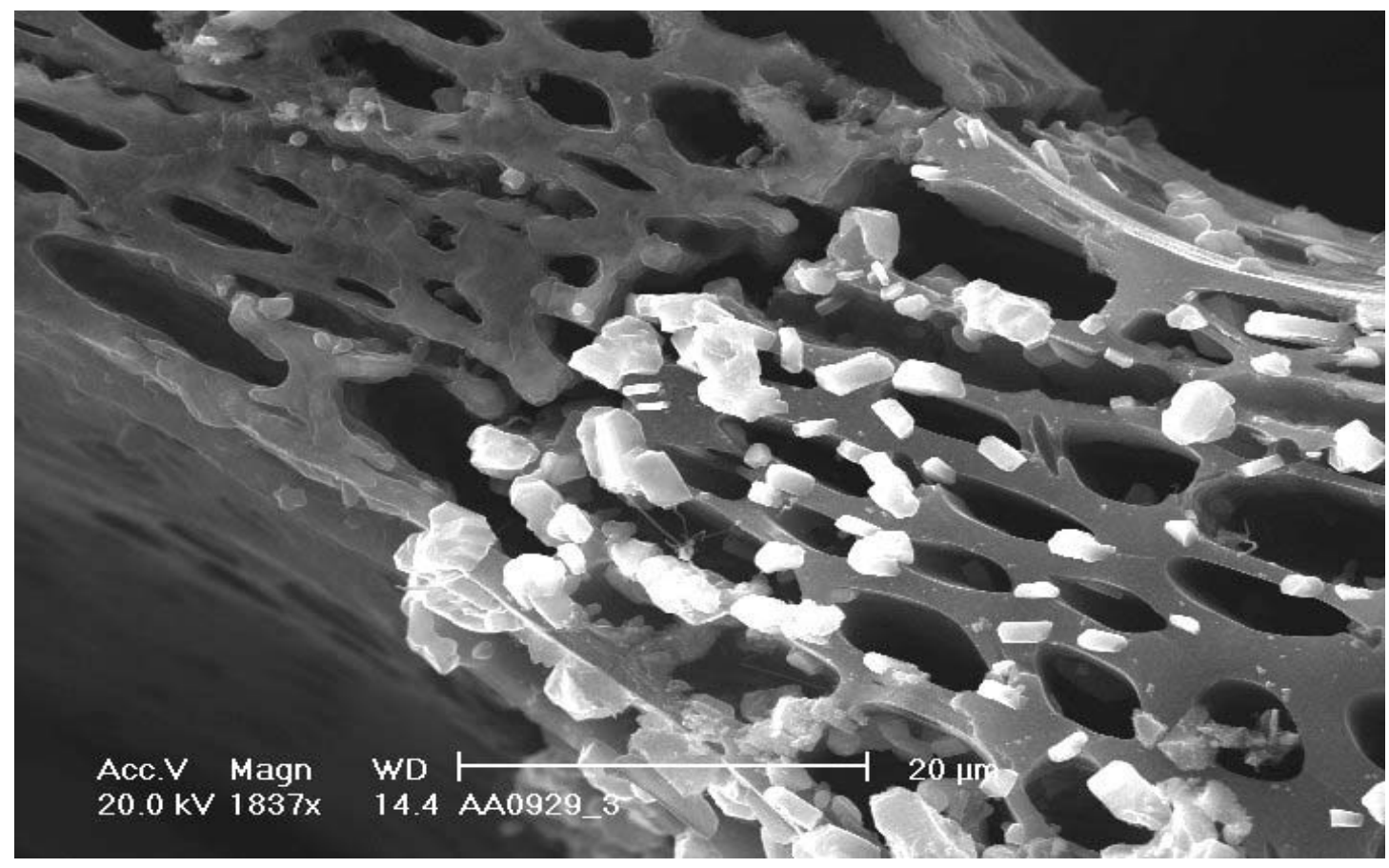

Figure 10a: Partially Reacted Wood Charcoal Showing $\mathrm{Al}_{4} \mathrm{C}_{3}$ Crystal Growth. 


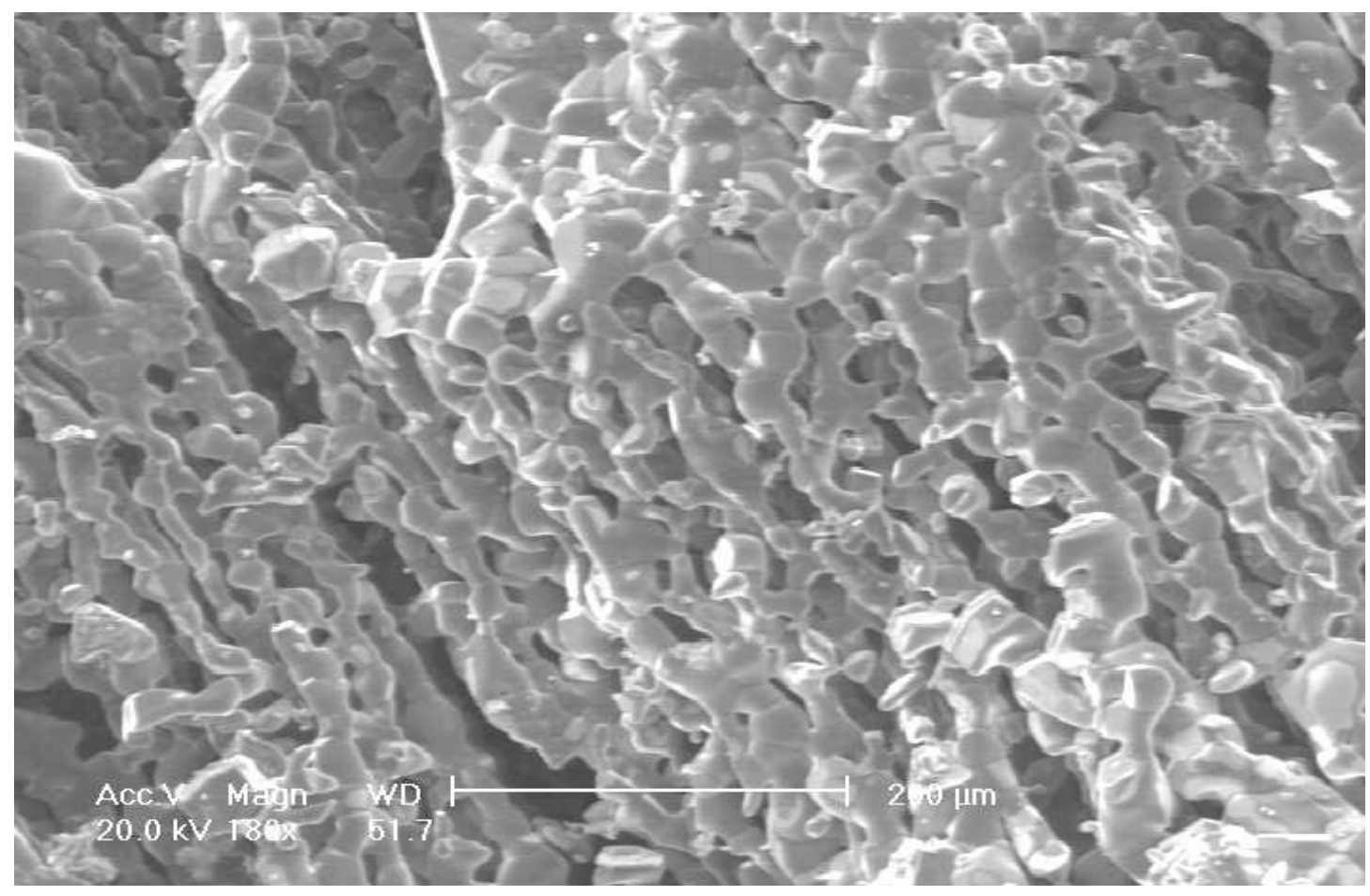

Figure 10b: Fully Reacted Wood Charcoal.

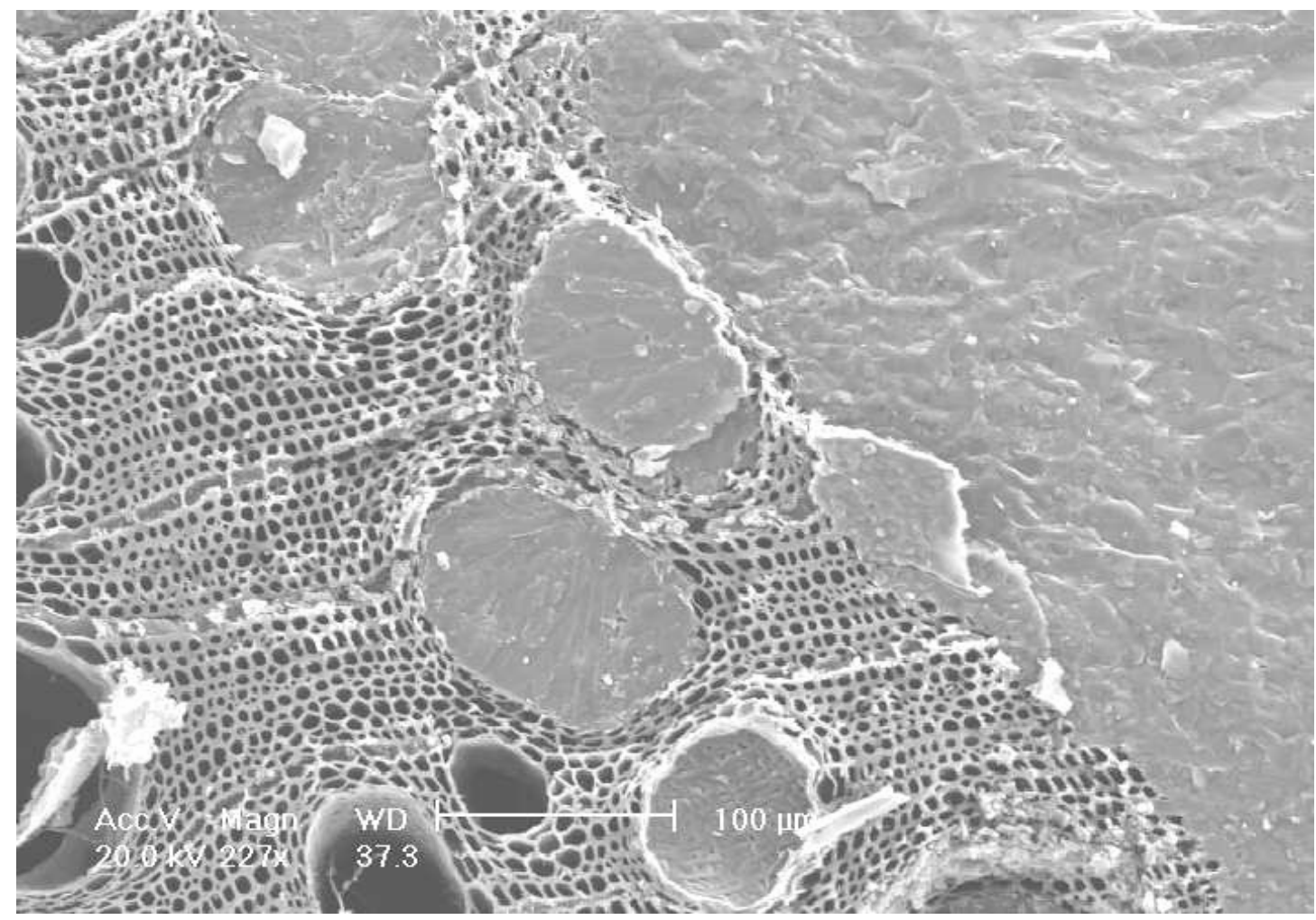

Figure 11: Dense Slag Formed on Wood Charcoal Surface. 
The conclusions from the experimental results are as follows:

1. The rate of $\mathrm{Al}_{4} \mathrm{C}_{3}$ formation from $\mathrm{Al}_{2} \mathrm{O}$ and $\mathrm{Al}$ gases in $\mathrm{CO}$ is controlled by the diffusion of the reactants through the $\mathrm{Al}_{4} \mathrm{C}_{3}$ product layer.

2. The critical parameters determining the rate are the effective diffusivities which were estimated to be 0.82 and $1.31 \mathrm{~cm}^{2} / \mathrm{s}$ for $\mathrm{Al}_{2} \mathrm{O}$ and $\mathrm{Al}$ respectively at $1950^{\circ} \mathrm{C}$ in the $\mathrm{Al}_{4} \mathrm{C}_{3}$ layer formed from wood charcoal.

3. Based on current knowledge of the thermodynamics of the relevant systems $\mathrm{Al}_{2} \mathrm{O}$ is responsible for over $90 \%$ of the carbide formed. Its vapor pressure is much higher than that of $\mathrm{Al}$ and has two atoms of $\mathrm{Al}$ while its effective diffusivity is only about $37 \%$ lower.

4. The only carbon type tested that reacted extensively was wood charcoal. The wood charcoal has a high $(60 \%)$ and uniform porosity. It is speculated that, when there is insufficient porosity, the increase in volume of the solid phases due to the formation of the carbide fills the pores and causes the reaction to stop. The wood charcoal also is very low in ash, which is a process requirement.

5. The largest uncertainty in the present work is accurately defining the driving force for diffusion, which depends on the thermodynamics of the system. Therefore, validation of the pressures of $\mathrm{Al}_{2} \mathrm{O}$ and $\mathrm{Al}$ generated by the reactions was determined experimentally. That work is described in the next section.

\section{Vapor Pressures of $\mathrm{Al}_{2} \mathrm{O}$ and $\mathrm{Al}$ in Equilibrium with $\mathrm{Al}_{4} \mathrm{C}-\mathrm{Al}_{2} \mathrm{O}_{3} \mathrm{Slag}$ at $1950^{\circ} \mathrm{C}$ to $2020^{\circ} \mathrm{C}$}

Knowledge of the vapor pressures of $\mathrm{Al}_{2} \mathrm{O}$ and $\mathrm{Al}$ in equilibrium with $\mathrm{Al}_{4} \mathrm{C}_{3}-\mathrm{Al}_{2} \mathrm{O}_{3}$ slag at high temperatures $\left(1950^{\circ} \mathrm{C}\right.$ to $\left.2020^{\circ} \mathrm{C}\right)$ is critical for evaluation and control of carbothermic reduction for producing aluminum. As indicated, the vapor pressures were experimentally determined ${ }^{(5)}$. The experimental setup was similar to that used in the previous study on the reaction of $\mathrm{Al}_{2} \mathrm{O}$ and $\mathrm{Al}$ gases with carbon. The change in weight of the slag and crucible and the weight and nature of the condensate on the crucible walls were measured. In addition, the total amount of $\mathrm{CO}$ released during the experiment was measured using a mass spectrometer. The mass spectrometer also measured the $\mathrm{Ar}, \mathrm{CO}_{2}, \mathrm{H}_{2} \mathrm{O}$, and $\mathrm{N}_{2}$ concentrations, which were used in the data analysis. In theory, the weight loss of the crucible and slag should indicate the weight of all the species leaving the system $(\mathrm{CO}$, $\mathrm{Al}_{2} \mathrm{O}$, and $\mathrm{Al}$ ). The measured mass of $\mathrm{CO}$ can then be deducted to determine the total amount of $\mathrm{Al}_{2} \mathrm{O}$ and $\mathrm{Al}$ lost from the melt. It is not possible to distinguish the loss of $\mathrm{Al}_{2} \mathrm{O}$ from $\mathrm{Al}$. Thermodynamics indicate that in the temperature range of interest $\left(1950^{\circ} \mathrm{C}\right.$ to $2020^{\circ} \mathrm{C}$ ), the $\mathrm{Al}_{2} / \mathrm{Al}$ molar ratio is 2.6 to 2.8 . This ratio only depends on the free energy of formation of $\mathrm{Al}_{2} \mathrm{O}$ and its uncertainty is estimated to be less than 10 pct. In any case, about $80 \%$ of the $\mathrm{Al}$ lost from the melt is as $\mathrm{Al}_{2} \mathrm{O}$. In the estimation of the $\mathrm{Al}_{2} \mathrm{O}$ pressure, a value for the ratio of 2.7 was used in this work.

The volume of $\mathrm{CO}$ leaving the reactor was calculated from the mass spectrometer data and the Ar flow rate. The mole percentage ratio of $\mathrm{CO}$ to $\mathrm{Ar}(\% \mathrm{CO} / \% \mathrm{Ar})$ was multiplied by the Ar flow rate ( $0.50 \mathrm{~L}$ STP per minute) and integrated with respect to time. The $\mathrm{CO}$ to $\mathrm{Ar}$ ratio remained relatively constant ( $\pm 5 \%$ ) over long periods of time (10 to 30 minutes). The $\mathrm{N}_{2}$ to Ar ratio was also measured and used to compute air ingress into the system and the 
amount of $\mathrm{CO}$ produced by oxidation of the graphite crucible by oxygen. The $\mathrm{CO}_{2}$, typically 0.2 to $1.0 \%$, was added to the $\mathrm{CO}$ since it was formed from $\mathrm{CO}$ by reaction with oxygen in the air ingressed into the system.

The experimental results are presented in Table 2. The measured values of the vapor pressures are in general agreement with the thermodynamic predictions. Specifically, the activity of $\mathrm{Al}_{2} \mathrm{O}_{3}$ at $\mathrm{Al}_{4} \mathrm{C}_{3}$ saturation predicted from the solution models and the standard free energy of the reactions of $\mathrm{Al}_{2} \mathrm{O}_{3}$ with carbon to form $\mathrm{Al}_{2} \mathrm{O}$ and $\mathrm{Al}$ vapors are consistent with the present measurements.

Table 2: Measured and Predicted $\mathrm{Al}_{2} \mathrm{O}_{3}$ Pressures During Slag Making

\begin{tabular}{|c|c|c|c|c|}
\hline $\begin{array}{c}\text { Temperature } \\
\left({ }^{\circ} \mathrm{C}\right)\end{array}$ & $\begin{array}{c}\mathrm{Al}_{2} \mathrm{O} \\
(\mathrm{Atm}) \\
\text { Measured }\end{array}$ & $\begin{array}{c}\mathrm{Al}_{2} \mathrm{O} \\
\text { (Atm) Qui- } \\
\text { Metselaar }{ }^{(2) * *}\end{array}$ & $\begin{array}{l}\mathrm{Al}_{2} \mathrm{O}(\mathrm{Atm}) \\
\text { Motzfeldt } \\
\text { et al. }{ }^{(6) * *}\end{array}$ & $\begin{array}{c}\text { Ar } \\
\text { (Atm) }\end{array}$ \\
\hline 1950 & 0.056 & 0.028 & 0.032 & 0.10 \\
\hline 1965 & 0.040 to $0.045^{+}$ & 0.050 & 0.063 & 0.10 \\
\hline 1980 & 0.090 & 0.079 & 0.095 & 0.30 \\
\hline 2000 & 0.122 & 0.082 & 0.100 & 0.10 \\
\hline 2020 & 0.110 & 0.112 & 0.146 & 0.10 \\
\hline
\end{tabular}

* General uncertainty is +15 pct.

** Degterov and Pelton's ${ }^{(7)}$ evaluation of the Qui-Metselaar ${ }^{(2)}$ model.

$+\quad$ Scatter due to large scatter in mass spectrometer. 


\section{COMPUTER MODELING}

\section{CMU Programs}

The CMU modeling program was conducted by two $\mathrm{PhD}$ students working under the supervision of Professor Erik Ydstie. One program focused on (a) the development of a model for the vapor recovery reactor (VRR) distributed in time and one spatial dimension and (b) the development of a simple total process model. The other program focused on developing steady state fluid flow models of the second reactor stage including an electric potential model (distributed in 3D) and heat transfer and fluid flow models distributed in 2D. Both PhD students continued their work as Postdoctoral students for a period of time after they had successfully completed their PhD defense.

\section{Program A: Vapor Recovery Reactor for Carbothermic Aluminum Production. PhD Student: Vianey Garcia-Osorio}

The primary objective of this research was to develop distributed parameter models for the vapor recovery reactor in the carbothermic aluminum process and then to include this model in a total process model. The latter was only partially successful due to the computational complexity involved in solving the coupled model structure and lack of efficient methods for stabilizing the simulation.

Three distinct models were developed for the VRR. All models treated the VRR as a packed bed filled with carbon particles that were small relative to size of the column. The aluminum containing gases entered at the bottom of the column and reacted with the carbon particles as they flowed up. The objective of the study was to explore carbon conversion factors and recovery rates for different column design parameters and operating conditions. The solid-gas reactions were based on the mass transfer limited (shrinking core) reaction scheme. This gives a mass transfer limited model with solid-vapor reaction rate determined by the mass transfer rate with the carbon particle. The diffusion rates for $\mathrm{Al}_{2} \mathrm{O}$ and $\mathrm{Al}$ reactants and $\mathrm{CO}$ product in the particle were based on experimental studies performed at Alcoa. The models furthermore assumed the following:

1. The size of the particle was considered to be constant.

2. There was no sintering.

3. The reactions were reversible.

4. The diffusion of the gas through the product layer controlled the rate of mass transfer.

5. There was no transport in the radial direction.

6. Temperature gradients within the solid particle were neglected.

Model A1: The Stage-wise VRR Model: The VRR was modeled using four distinct reaction zones with preset temperature. The concentrations and heat duties for each of the stages were calculated and overall conversion factors determined. This model and the results were published ${ }^{(8)}$. 
Model A2: The Continuous Fixed Bed VRR Model: The VRR was modeled as a plug flow continuous fixed bed reactor with axial dispersion. There was no reaction in the vapor phase. The shrinking core model was used to determine the local reaction rate. A number of case studies were developed to study the sensitivity of the model outputs (conversion and recovery) versus design parameters (superficial velocity, column height and particle diameter). The model temperature and conversion predictions compared favorably $(+-15 \%$ for conversion) with a small scale experimental column. The numerical method for solving the system relied on discretization using the method of lines. The MATLAB routine ODE15S was used to solve the resulting set of differential algebraic equations ${ }^{(9)}$.

Model A3: The Moving Bed VRR Slag Model: The VRR was modeled as a plug flow continuous, counter current, moving bed reactor with axial dispersion. Reaction in the vapor phase was modeled by assuming that the Al-O-C system was at equilibrium at a given pressure and temperature. Equilibrium data was generated using model parameters from the FACT data base system. The shrinking core model was used to determine the local reaction rate inside the carbon pellet. The model was used to study the sensitivity of conversion and recovery with respect to design parameters like gas superficial velocity, carbon feed rate and gas composition. The model showed that slag could be generated in the column. The formation of slag may cause operational problems since the column can become very difficult to operate. The model description and results were published ${ }^{(10)}$. A theoretical framework was also developed for studying the stability and convergence of control strategies for reaction diffusion convection reaction problems ${ }^{(11)}$.

Model A4: The Total Process Model: The VRR model was combined with dynamic models for Stage 1 and Stage 2. These models were based on assumed values for a production system and connected together and integrated with thermo-physical properties models to establish the time dependent compositions of Stages 1 and 2. It proved to be very difficult to solve the resulting large scale system of differential algebraic equations. We therefore developed a new modular simulation method for integrating distributed simulation models. This approach is described and tested on a very simple system ${ }^{(12)}$. The simulation model was not completed due to difficulties concerning the linking the FACT thermophysical properties data base system with the MATLAB/SIMULINK system for process modeling and control system design.

A complete description of these models and related results is given in $\mathrm{Dr}$ V. GarciaOsorio's $\mathrm{PhD}$ thesis.

\section{Program B: CFD Modeling of Stage 2 of the Carbothermic Aluminum Process. PhD Student: Dimitrios Gerogiorgis}

The objective of this work was to develop CFD models to study the interaction of current, heat and fluid flow in the second stage of the carbothermic aluminum process. Several different models were developed.

Model B1: Thermo-physical Properties: In order to develop the CFD model it was first needed to develop temperature and composition dependent thermo-physical properties for 
the Al-O-C system in the temperature range $1900-2020^{\circ} \mathrm{C}$. Very little data is available and in some instances we had to rely on data taken from other systems (e.g. substituting Al with Boron). Correlations were then developed for density, viscosity, thermal and electrical conductivity as well as melting points ${ }^{(13)}$.

\section{Model B2: Mixed Integer Nonlinear Programming Model for Optimal Voltage: A} Mixed Integer Nonlinear Programming Model (MINLP) was developed for investigating the optimal voltage input to a furnace with 6multiple electrode pairs. The reactor was modeled as a compartmentalized system with multiple well mixed compartments. The concentration, temperature and energy requirements were modeled using a kinetic model for the Al system. The model was developed using the GAMS modeling environment for optimization. The nonlinear program was solved to local optimality using the GAMS MINLP model. The model solved robustly. The optimal energy inputs and process flows were determined using less than 30 minutes of computer time ${ }^{(14)}$.

\section{Model B3: CFD Model for Fluid Flow Calculation in Stage 2 of the Carbothermic Aluminum Process: The full reactor and homogeneous slag assumptions were used in order to simplify the many physical phenomena and study electric charge, heat and momentum balances. The goal was to solve the steady state PDE problems for the respective variables of the latter balances [potential $(\mathrm{V})$, field intensity $(\mathrm{E})$, temperature $(\mathrm{T})$, velocity $\left(U_{x}, U_{y}\right)$, pressure $\left.(P)\right]$, obtaining reliable starting points so as to solve molar balances for species concentration profiles in a complete model reliable for performance evaluation. Constant thermo-physical properties were assumed, although a temperature- dependent electrical conductivity was used to illustrate the strong coupling between the charge balance and the Joule heat generation term. The standard k- $\varepsilon$ model of Launder and Spalding was used in the momentum balance in order to analyze the turbulent slag flow in the reactor. A CFD model of the Stage 2 of the process was developed. The model is based on the assumption of incompressible fluid flow.}

The finite element method was used to formulate the PDE problem on an unstructured triangular domain discretization. The developed finite element model of the reactor has been solved with quadratic finite element basis functions, using a commercial finite element simulation environment (FEMLAB ${ }^{\circledR}$ v. 2.3). Four FEMLAB ${ }^{\circledR}$ modules were used for these simulations: (a) "Conductive Media DC", (b) "Convection and Conduction", (c) "K- $\varepsilon$ Turbulence Model" and (d) "General form PDE Model". Imposed electrode voltages were crucial, affecting field intensity and current density profiles (hence Joule effect heat production). This in turn was expected to affect the uniformity of heat generation, thus the uniformity of temperature and gas fraction distributions. Slag convection was also influenced by the presence of electrodes. This study presents (a) pseudo-homogeneous slag CFD results derived without gas generation modeling and (b) two-phase flow CFD results that use a T-independent gas generation model.

There only experimental data available to test this model was the temperature data generated by the pilot experiments. The model matched temperature data very well. The two phase model predicted that there was considerable fluid mixing close to and above the electrodes. 
The CPU time required for convergence below tolerance when solving the quadruple PDE problem for specific voltages (Vi) was about $30 \mathrm{~min}$. (the corresponding grid has 3031 triangles). Solutions were obtained using reasonable computational resources (A dual processor Pentium III/1.2 GHz with $512 \mathrm{MB}$ of RAM was used in these studies). Finer discretizations were used to enhance the accuracy. The feasibility of developing a 3D model was investigated. It was concluded that the FEMLAB system would not be able to handle this problem for the full scale system at the present time.

The CFD models and the results were published ${ }^{(15-22)}$. A full description of the research results is given in the $\mathrm{PhD}$ thesis by Dr. Dimitrios Gerogiorgis.

\section{Alcoa Programs}

Early computer modeling work at Alcoa involved use of a program provided by Aspentech in which the FACT database was interfaced with Aspen. This software was employed to run mass and energy balances on various flow sheet concepts.

More recently, the Aspen software was upgraded to windows 11.1 and CHEMAPPS software was obtained since it is required to implement and trouble shoot Aspen/FACT. Mass and energy balances were calculated for several operating scenarios, with the base case being carbon saturation in Stage 2. Specific cases run included the effect of $\mathrm{Al}_{4} \mathrm{C}_{3}-\mathrm{Al}$ recycle from metal recovery on Stage 2; the effect of heat additions to the inlet zone of the vapor recovery operations; and the impact of adding $\mathrm{Al}_{2} \mathrm{O}_{3}$ to the vapor recovery step. Results expressed as net electrical energy required ranged from 7.84 to $14.1 \mathrm{kWh} / \mathrm{Kg}$ for the base case optimistic to pessimistic assumed conditions. With heat additions to vapor recovery, the range was 7.54 to $13.2 \mathrm{kWh} / \mathrm{kg}$. For $\mathrm{Al}_{2} \mathrm{O}_{3}$ additions to vapor recovery in addition to heat, the energy rates were 6.38 to $11.2 \mathrm{kWh} / \mathrm{kg}$ for optimistic to pessimistic conditions.

The optimistic assumptions include utilization of the process waste heat from the vapor recovery step, the heat value of the $\mathrm{CO}$ off-gas and the sensible heat of the metal product to preheat input materials to the process, where the input materials are $\mathrm{Al}_{2} \mathrm{O}_{3}$ and petroleum coke to Stage 1, and vapor recovery solids discharge plus recycle dross fraction from Al-C separation to Stage 2. Heat additions to the inlet of the vapor recovery column are needed to drive the reactions of $\mathrm{Al}$ and $\mathrm{Al}_{2} \mathrm{O}$ with carbon to form $\mathrm{Al}_{4} \mathrm{C}_{3}$. Alumina additions to vapor recovery capture the sensible heat of the reaction gases in the upper regions of the vapor recovery column by forming $\mathrm{Al}_{2} \mathrm{O}_{3}-\mathrm{Al}_{4} \mathrm{C}_{3}$ slag which then converts to $\mathrm{Al}_{4} \mathrm{C}_{3}$ in the lower column zones.

In addition to the CMU and ATC calculations, independent calculations were conducted by Elkem based on simple equilibrium conditions at 100\% thermal efficiency, varying carbon conversion to carbide in the vapor recovery step, some of the alumina feed going through the vapor recovery unit and all of the carbon feed going through as well. These calculations were done using Chemsheet software. Model results using Chemsheet were similar to those for Aspen/FACT. Thermodynamics do not appear to limit the potential of the process. In 
follow-up calculations, Elkem predicted a range of net energy requirements from $9.5 \mathrm{kWh} / \mathrm{kg}$ to $11.6 \mathrm{kWh} / \mathrm{kg}$ for a reactor system thermal efficiency of $80 \%$ and a credit for $\mathrm{CO}$ to power conversion at $35 \%$ efficiency.

The initial Alcoa work on a Stage 1 model was done using CFX4 computational fluid dynamic software. Progress was made in coupling current flow, joule heating, heat flow, natural convection and sidewall freezing. However, CFX did not handle the geometric complexities of the model and new software was considered. CFX 5 upgrade does have the capability to address the geometric complexities since it can create its own unstructured mesh. The Stage 1 model development is continuing using CFX5. 


\section{REACTOR DEVELOPMENT}

Major design challenges from earlier efforts to develop a carbothermic reduction process for aluminum were reviewed and a tailor-made multi-stage reactor design and processing concept has been developed, based on utilizing Elkem's proprietary reactor technology.

A modular test program was designed to demonstrate the technical feasibility of the process concept. Several successful test campaigns were conducted verifying the technical feasibility of the first stage and critical elements of the second stage. Additional module tests were done on the vapor recovery step. The tests have been performed in large laboratory scale units designed to operate in the $0.5-1.6 \mathrm{MW}$ range. All results from the modular tests will be used to design an integrated reactor, which will be constructed and operated to verify all of the stages combined.

Stage 1 campaigns were designed for equipment "shake-down", determination of reactor system characteristics, evaluations of process parameters and to establish the reactor operating strategies. These campaigns were highly successful and proved the feasibility of the pre-reduction stage:

- Pre-reduced slag with controlled carbon content was produced.

- The slag was manageable both in the reactor and during tapping.

- The test system functioned as planned and no flaws or weaknesses in the basic engineering design were detected.

The following photos indicate both the complexity of the test installation and the level of ambition for the test work.

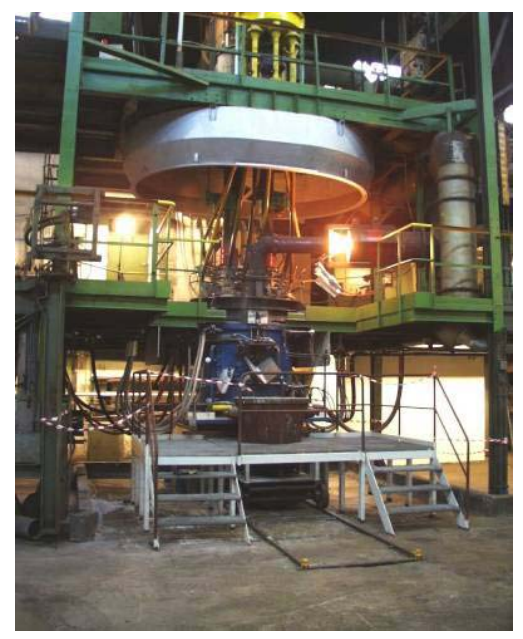

Figure 12: Overview of the Experimental Site for Stage 1. 


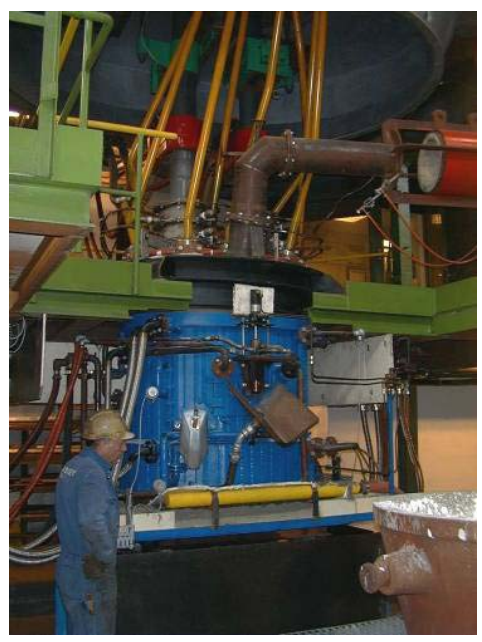

\section{Figure 13: Front View of the Stage 1 Reactor.}

Following the successful demonstration of Stage 1 feasibility, the laboratory facility was modified to develop Stage 2. A $500 \mathrm{~kW}$ module was installed and operated to evaluate horizontal, sidewall-entering electrode assemblies, electrode slippage, reactor sidewall controlled cooling systems, slag composition control and tapping of slag. Temperatures up to $2100^{\circ} \mathrm{C}$ were measured. A number of successful tests were run, verifying these critical components and providing valuable input for the design of a large scale integrated system. Figure 14 shows the Stage 2 module setup for an early test operated without a lid to study slag flow patterns during powering of the sidewall electrodes.

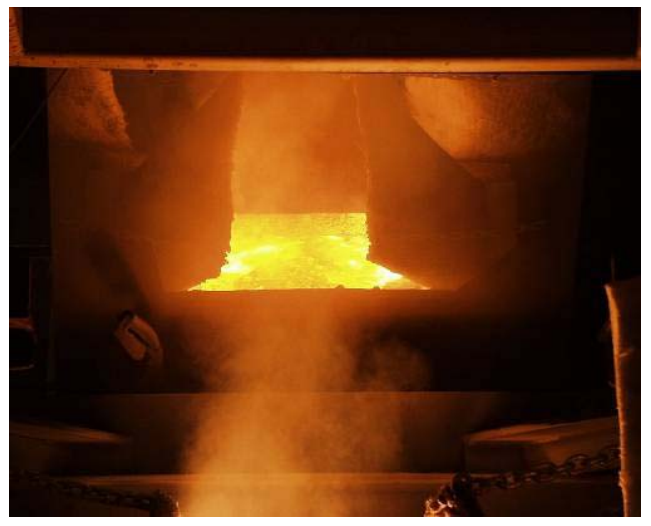

Figure 14: Stage 2 Module with Lid Removed Showing Molten Slag Flow.

The Stage 2 module also functioned as a generator of reaction gases for laboratory testing of a vapor recovery system. A prototype vapor recovery reactor module was installed and used to determine functional system solutions and design parameters. Hot process gas transport requirements were obtained. Gas inlet temperatures greater than $1820^{\circ} \mathrm{C}$ were measured. Gas, composed of $95 \% \mathrm{CO}$, exited the column at greater than $1000^{\circ} \mathrm{C}$. 
On-line mass spectrometry was employed to analyze process gases. The use of metered Ar as a tracer in conjunction with the gas analysis provided an estimate of the total gas flow rate.

Test results from operation of the prototype vapor recovery module will be used to aid design of vapor recovery for the integrated system.

The focus for the 2004 program was on the design, assembly and evaluation of an advanced Stage 1 and VRR 1 system for the $3 \mathrm{MW}$ integrated reactor. The engineering solutions chosen for the advanced Stage 1/VRR 1 system are identical to those which are required for the total integrated reactor system, especially with respect to materials of construction and achieving structural integrity. Installation of Stage 1/VRR 1 was completed. The new Stage 1 is a 1.5 MVA system designed to operate between $0.5 \mathrm{MW}$ and $1.25 \mathrm{MW}$. The Vapor Recovery Reactor is a gas/solid counter-flow system with solids discharge.

Auxiliary systems for feed preparation, off-gas handling, synthetic media cooling and process monitoring/control have been designed for maximum flexibility and conform to industrial EHS standards. Great emphasis was placed on system robustness and the whole test installation conforms to commercial engineering standards.

A shake-down test was run to check out the functionality of the equipment. The system is being prepared for a hot slag test in the first quarter of 2005.

The pictures in Figures 15 and 16 show the test site, the infrastructure and some of the auxiliary equipment.

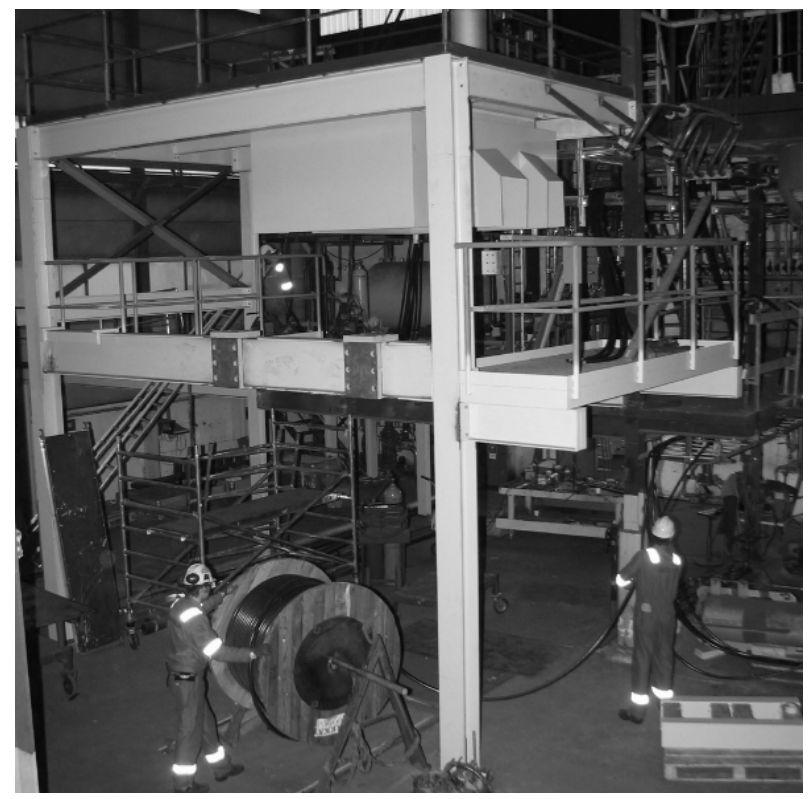

Figure 15: Test Site. 


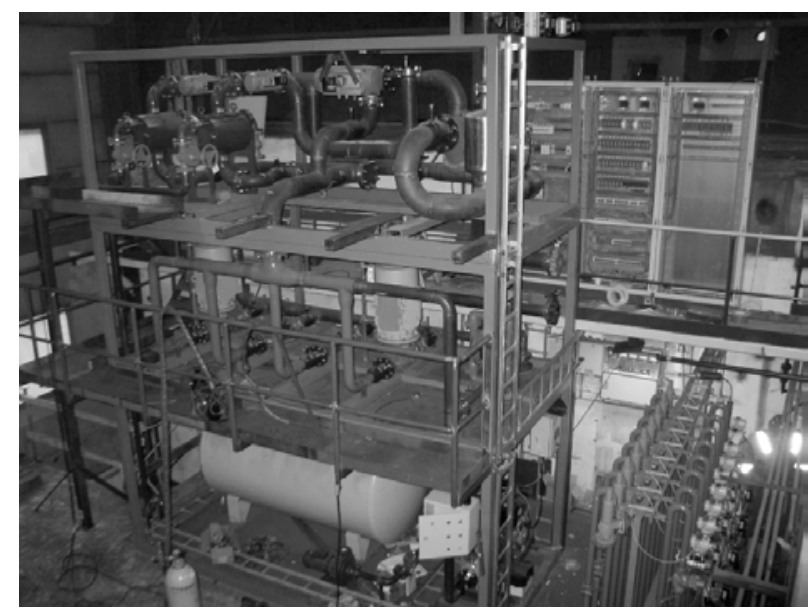

Figure 16: Oil Coiling System.

In addition to the Stage 1/VRR 1 system, research continued on VRR design and operation, and on a new concept for solids charging to Stage 1 . Reliable vapor recovery tests must have the correct ratio between reaction gases and VRR charge flow. The ratio depends on the composition of the slag and the amount of carbon available for vapor recovery. Valuable information can be obtained from simple tests. Preferably such tests are smallscale simulations of the complete process. The temperature of the outgoing gas is determined by the extent of the reactions in the vapor recovery reactor, and the reactions between gas and VRR charge can be studied.

A series of static as well as moving bed VRR experiments were run in order to investigate the mechanism and kinetics of the vapor recovery reactions. These experiments took place in both single and double electrode furnaces in the 50-150 kW range, Figure 17.

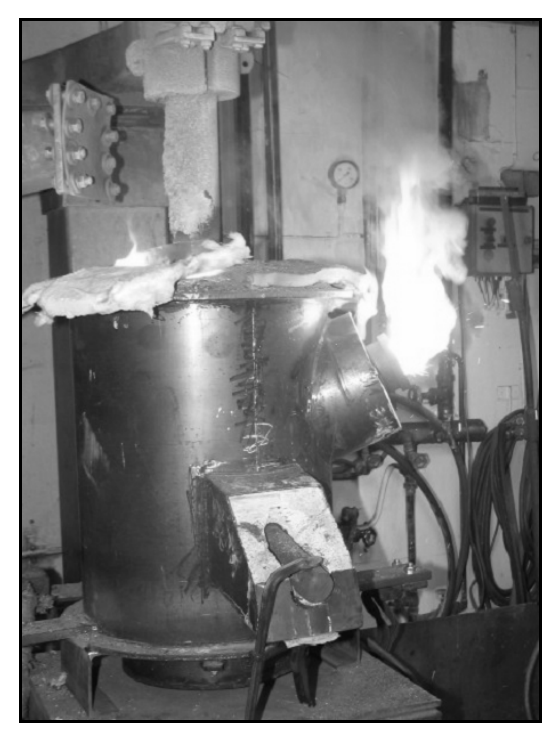

Figure 17: Static Bed VRR Experiment in a Single Electrode Arc Furnace. 
Countercurrent mechanical operation was demonstrated. Conditions for $\mathrm{Al}_{4} \mathrm{C}_{3}$ formation were established. Figure 18 is an example of almost complete conversion of VRR charge in a dynamic test.

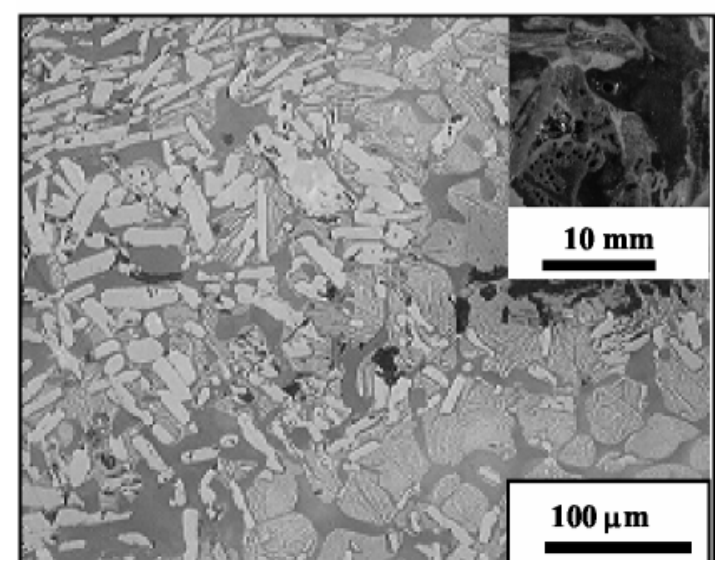

Figure 18: Converted VRR Charge.

Following the VRR tests, the small arc furnace was modified to facilitate evaluation of the new solids charging concept. The concept was demonstrated, although the scale of the experimental unit limited the ability to obtain quantitative data for operating parameters. It was determined that further testing would be more effective at a larger scale. Therefore, the charging system has been included in the advanced Stage 1/VRR 1 unit. 


\section{DECARBONIZATION DEVELOPMENT}

Decarbonization is the fourth stage of the Advanced Reactor Process (ARP) and is critical to the recovery of commercial grade $\mathrm{Al}$ from the $\mathrm{Al}-\mathrm{C}$ reaction product tapped from Stage 2 of ARP.

Both Pechiney and Reynolds have reported R\&D on decarbonization of carbothermically produced Al-C alloys. Pechiney reported that alloys containing $30 \% \mathrm{Al}_{4} \mathrm{C}_{3}$ would not tap from their electric furnace. Alloys with $15 \% \mathrm{Al}_{4} \mathrm{C}_{3}$ did tap easily. As a result, Pechiney adjusted their slag concentration to reduce the carbon content of the metal product. The resulting alloy analyzed $85 \% \mathrm{Al}-13 \% \mathrm{Al}_{4} \mathrm{C}_{3}-2 \% \mathrm{Al}_{2} \mathrm{O}_{3}$. Reports by Reynolds on $\mathrm{Al}_{2} \mathrm{O}_{3}$ extraction tests were studied. Reynolds used a mixture of $70 \% \mathrm{Al}_{2} \mathrm{O}_{3}-30 \%$ slag (containing $85 \% \mathrm{Al}_{2} \mathrm{O}_{3}-15 \% \mathrm{CaO}$ ), which equates to $95.5 \% \mathrm{Al}_{2} \mathrm{O}_{3}-4.5 \% \mathrm{CaO}$. The $\mathrm{CaO}$ was added to reduce the melting temperature of the extractant. Starting at an average concentration of $8.4 \% \mathrm{Al}_{4} \mathrm{C}_{3}$ in the metal, the average final concentration was $2.1 \%$ or a $75 \%$ reduction. Temperatures during extraction were in the range of $1700^{\circ} \mathrm{C}$ to $1900^{\circ} \mathrm{C}$. Recovery of $\mathrm{Al}$ was about $50 \%$. Although the addition of $\mathrm{CaO}$ was effective in providing a liquid phase extractant, the use of $\mathrm{CaO}$ commercially is unlikely since the oxide reduces to $\mathrm{Ca}$ which concentrates in the product metal phase. Alumina extraction is desirable, especially if it takes place in the reactor rather than in a separate furnace as patented by Reynolds.

Alcoa's work on this task was initiated in 2002. Several process options were considered, including $\mathrm{Al}_{2} \mathrm{O}_{3}$ extraction, controlled cooling of the $\mathrm{Al}-\mathrm{C}$ alloy to effect phase separation of solid $\mathrm{Al}_{4} \mathrm{C}_{3}$ from liquid $\mathrm{Al}$, and extraction by chloride salts.

The Reynolds $\mathrm{Al}_{2} \mathrm{O}_{3}$ extraction concept was evaluated. Several tests were run in alumina crucibles to avoid carbon contamination by reaction with graphite containers. Although some carbide was removed, the $\mathrm{CaO}$ attacked the alumina crucibles. Further testing of the $\mathrm{Al}_{2} \mathrm{O}_{3}$ extraction was put on hold to assess other options.

Feasibility of $\mathrm{Al}_{4} \mathrm{C}_{3}$ extraction by chloride salts was tested. The results were promising. Up to $65 \%$ of the charge was recovered as carbon free coalesced $\mathrm{Al}$, which was at least $79 \%$ recovery of the available Al.

In 2003, separation tests were initiated on Al-C alloy produced by Elkem in the Stage 2 hot box module during a series of runs made in December 2002. Alloy feed compositions contained $1.26 \% \mathrm{C}$, equivalent to $\sim 5 \% \mathrm{Al}_{4} \mathrm{C}_{3}$ and $2.48 \% \mathrm{C}$, equivalent to $9.92 \% \mathrm{Al}_{4} \mathrm{C}_{3}$. The alloy was charged to alumina crucibles and heated to $760^{\circ} \mathrm{C}-960^{\circ} \mathrm{C}$ using a resistance-heated furnace. Various types of treatment were tested, including the effect of salt additions, inert gas sparging, mechanical stirring and dilution by $\mathrm{Al}$ additions. After treatment, the $\mathrm{Al}$ and "carbide dross" were separated by decanting. The dross was then screened through selected screen sizes. All resulting phases were analyzed for carbon content. The dross was also analyzed for free Al, oxygen and nitrogen. The metal was analyzed by ICP. For each test, the total mass balance and the Al product recovery were determined. Individual elemental balances were also determined for selected tests. 
Major conclusions from the tests were as follows:

- Al recovered from the various separation methods was very low in carbon content, typically less than $0.06 \%$.

- Inert gas sparging was effective in attaining good separation of Al from dross.

- Degree of separation was similar for the temperature range studied. Temperatures did not impact Al recovery.

- Dilution with Al did not improve the efficiency of separation for inert gas sparged tests.

- Based on a few tests, salt additions resulted in the highest Al recovery.

- Based on two tests, the initial carbon content of the alloy did not impact Al recovery.

- Mass balances were high for all tests; the lowest was 98.1\%; the average was greater than $99 \%$.

Simultaneous to the separation experiments on Stage 2 hot box alloy, Elkem developed a system for synthetically producing Al-C alloy to produce additional charge material for further separation trials. Temperatures of $2000^{\circ} \mathrm{C}$ or higher were attained in the melt. Alloy carbon concentrations ranged from about $1.5 \%$ to $3.5 \%$ in tapped alloy.

The Alcoa separation tests continued using the synthetic alloy made. Good Al recoveries were sustained for higher carbon (carbide) concentration alloys comparing results from processing of $3.5 \% \mathrm{C}$ alloy versus $2.48 \% \mathrm{C}$ alloy. In all separation tests, the dross phase has been dry, granular and free flowing. These properties are important to the dross recycle step of the Advanced Reactor Process.

Alcoa scaled up its separation tests by a factor of 10 using an induction furnace at Carnegie Mellon University (CMU). Synthetic alloy made at Elkem was charged, heated to $735^{\circ} \mathrm{C}$ $760^{\circ} \mathrm{C}$ and treated to effect separation of the $\mathrm{Al}$ from the $\mathrm{C}$. Conditions used in the Alcoa small scale runs were repeated in the $\mathrm{CMU}$ furnace. Initial $\mathrm{C}$ concentrations ranged from $1.6 \%$ to $3.75 \% \mathrm{C}$. Al recoveries of $94 \%$ or higher were attained. Carbon concentrations of the recovered $\mathrm{Al}$ phase were $0.06 \%$ or less. The carbide dross was dry and granular, well suited for recycle to the reactor. The CMU results verified those obtained in the Alcoa small scale experiments.

Three CMU tests were done at high temperatures, $1910^{\circ} \mathrm{C}$ to $2140^{\circ} \mathrm{C}$. In these tests, $\mathrm{Al}$ and $\mathrm{C}$ were charged to a graphite crucible, alloy was produced at $2.5 \%-5.0 \% \mathrm{C}$ and separation was carried out in-situ on the alloy at about $750^{\circ} \mathrm{C}$. Good $\mathrm{Al}$ recoveries were attained. 


\section{ECONOMIC ANALYSIS}

Successful development of ARP will potentially result in significant cost benefits for greenfield aluminum smelter installations, especially in locales that rely on fossil fuel power generation.

In 1999, prior to the start of the DOE project, a preliminary cost estimate was prepared to compare ARP with published world wide average costs for Hall-Heroult aluminum production. Table 3 shows the resulting total cost comparison between ARP and HallHeroult for a 400,000 metric ton per year smelter. The capital cost associated with a greenfield Hall-Heroult smelter was $\$ 4,000$ per MTY or $\$ 1.6$ billion, while the capital for ARP was $\$ 1,763$ per MTY or $\$ 705$ million. The preliminary operating cost comparison predicted a cash operating cost savings of $\$ 173$ per metric ton, or $\$ 69.2$ million for the sample plant. The energy rates used were $14.74 \mathrm{kWh} / \mathrm{Kg} \mathrm{Al}$ for Hall-Heroult and $9.50 \mathrm{kWh} / \mathrm{kg}$ Al for ARP. The total costs for carbothermic were about $30 \%$ lower for a $12 \%$ rate of return, at an estimated $\$ 587$ per metric ton savings. Energy, labor and capital charges were major positives and carbon cost was a negative for carbothermic.

Table 3: Estimated Total Cost Comparison for 400,000 MTY Al Production, \$/MT

\begin{tabular}{lcc}
\hline \multicolumn{1}{c}{ Cost Category } & $\begin{array}{c}\text { Hall-Heroult } \\
\text { WW Average }\end{array}$ & ARP \\
\hline Alumina & 398 & 386 \\
Carbon & 144 & 248 \\
Bath & 14 & 0 \\
Energy & 307 & 199 \\
Labor & 120 & 43 \\
R\&M materials & 66 & 30 \\
Pig casting & 31 & 31 \\
Overhead & 66 & 35 \\
Other & 78 & 78 \\
Cash operating cost & 1224 & 1051 \\
Capital charge $(12 \% \mathrm{~A} / \mathrm{T})$ & 741 & 327 \\
Total cost & 1965 & 1378 \\
\hline
\end{tabular}

It is estimated that ARP's production rate would be about 100 times greater than the largest Hall-Heroult cell (300 kiloamp). For a 400,000 MTY plant, Hall-Heroult would require 500 cells, whereas ARP would need 5 reactors. Obviously, this has a significant impact on reducing labor costs.

Later, the ARP cost comparison was upgraded to reflect the impact of a $29 \%$ lower predicted capital cost based on results from the development program through mid-2002. For the latest comparison, current benchmark cost estimates for Hall-Heroult were used. For this estimate, the energy rates used were $13.25 \mathrm{kWh} / \mathrm{kg}$ Al for Hall-Heroult and $9.50 \mathrm{kWh} / \mathrm{kg}$ Al for ARP. Table 4 shows the later comparison, for a 240,000 MTY facility. Total costs for carbothermic are about 35\% lower than Hall-Heroult, again based on a $12 \%$ 
return. The capital cost savings have the most significant impact on the cost reduction potential, similar to the 1999 study. Estimated capital costs for the 240,000 MTY plants are $\$ 960$ million $(\$ 4,000$ per MTY) for Hall-Heroult and $\$ 300$ million $(\$ 1,250$ per MTY) for ARP.

One scenario for ARP is to add scrap to the high temperature Al-C metal phase product. Benefits of this approach include cooling the metal phase for further processing (e.g., casting) by a method that effectively uses the metal phase sensible heat (i.e., melting the scrap). This has an energy cost value of about \$22/MT Al for melting, plus an environmental benefit of eliminating the $\mathrm{CO}$ that would be generated by conventional combustion melting of the scrap.

Another consideration is to co-locate carbothermic plants with existing fabricating plants. Co-located carbothermic facilities creates the possibility of mixing primary metal with a continuous stream of recycled metal, which would offer significant economic advantages. In addition, carbothermic facilities could be sized according to fabricating plant needs, rather than rely on increasing capacity to offset capital costs, as is the case with Hall-Heroult plants. Economic savings, therefore, would vary by plant on a case-by-case basis.

Table 4: Estimated Total Cost Comparison for 240,000 MTY Al Production, \$/MT

\begin{tabular}{lcc}
\hline \multicolumn{1}{c}{ Cost Category } & $\begin{array}{c}\text { Hall-Heroult } \\
\text { Benchmark }\end{array}$ & ARP \\
\hline Alumina & 359 & 359 \\
Carbon & 101 & 288 \\
Bath & 10 & 0 \\
Energy & 239 & 180 \\
Labor & 101 & 19 \\
R\&M materials & 156 & 14 \\
Pig casting & 33 & 33 \\
Overhead & 45 & 2 \\
Other & 0 & 29 \\
Cash operating cost & 1043 & 924 \\
Capital charge $(12 \%) \mathrm{A} / \mathrm{T})$ & 741 & 232 \\
Total cost & 1784 & 115 \\
\hline
\end{tabular}

The energy values for $\mathrm{CO}$ off-gas from the vapor recovery reactors is typically estimated by assuming a $30 \%$ efficiency in generation of power by combustion of the $\mathrm{CO}$. In an effort to optimize capture of $\mathrm{CO}$ energy values, Fern Engineering was retained to conduct a paper study on $\mathrm{CO}$ energy utilization. Various concepts were defined, conversion efficiencies to power were predicted and capital costs were estimated. For the options evaluated, the net efficiencies ranged from about $31 \%$ to $47 \%$; estimated capital costs varied from $\$ 267$ per $\mathrm{kW}$ to $\$ 1507$ per $\mathrm{kW}$. The most promising option was a simple GE gas turbine fired on CO using a natural gas supplement to satisfy the inlet flow requirements for that specific turbine. This option did not include $\mathrm{CO} 2$ recovery. 
Alcoa is exploring potential opportunities for commercialization of carbothermic in the United States, including automotive, extrusion and smelting applications. Scenarios being considered include smaller carbothermic reactors to supply Al to "mini-mill" type applications for casting plants in the range of 15,000 to $25,000 \mathrm{mt} / \mathrm{yr}$ production. Rolling mills can range from 14,000 mt/yr to $180,000 \mathrm{mt} / \mathrm{yr}$. Extrusion plants also have a wide range of productivity, up to about $80,000 \mathrm{mt} / \mathrm{yr}$. On-site smelting at a fabrication plant will save transportation costs to ship ingot plus the melting costs. This can be a 3 to 5 cent/lb savings. Also, power contracts are generally more available and lower cost for smaller segments of purchased power. 


\section{ACCOMPLISHMENTS}

The project accomplishments are summarized in the following list.

- The system thermo-chemistry was defined for the Advanced Reactor Process flow diagram.

- An operating diagram was developed based on available thermodynamics for the $\mathrm{Al}_{2} \mathrm{O}_{3}-\mathrm{Al}_{4} \mathrm{C}_{3}$ system.

- Correlations for slag and metal alloy viscosities versus temperature and composition were predicted from developed mathematical expressions.

- Stage 1 was demonstrated at the $1 \mathrm{MW}$ scale.

- Stage 2 critical components were demonstrated in a $500 \mathrm{~kW}$ module.

- The fundamentals of vapor recovery were experimentally determined, including reaction mechanisms and $\mathrm{Al}$ species vapor pressures.

- The detailed design and installation of an advanced Stage 1 system was completed, including a vapor recovery reactor.

- The feasibility of efficient $\mathrm{Al}-\mathrm{C}$ separation was demonstrated.

- Capital and operating cost estimates for the process were updated.

- Computer models were developed for the vapor recovery system and are in progress for Stage 1, Stage 2 and the total process.

- A number of papers were presented and published in Light Metals and other journals and/or conference proceedings.

- Five US patents have been awarded; 3 patent applications are in process of being reviewed by the US Patent Office.

\section{CONCLUSIONS}

Based on the progress through December 31, 2004 we have concluded that (1) the thermodynamics of the process are valid; (2) the designs of the Stage 1 and Stage 2 reactor components successfully address the identified technical hurdles related to the prereduction and reduction process steps; (3) efficient decarbonization of the Al-C alloy product is feasible; (4) fundamentally, the vapor recovery process concepts are valid; (5) the process economics are favorable compared to the Hall-Heroult process for production of commercial grade Al; and (6) that the program should continue with emphasis on the engineering of the vapor recovery system, followed by the implementation of a $3 \mathrm{MW}$ totally integrated reactor system to demonstrate all steps of the process and to develop additional design data for a large scale pilot reactor system.

\section{RECOMMENDATIONS}

It is recommended that the program be continued through the $3 \mathrm{MW}$ integrated reactor evaluation. Based on the results of test campaigns with the integrated reactor, plus a further update on process cost estimates, the next phase of study would be the design and implementation of a large scale pilot reactor. 


\section{REFERENCES}

1. K. Motzfeldt, B. Sandberg and S. Julsard: Molten Aluminum Oxycarbide Considered as an Ionic Mixture, High Temperature Materials and Chemistry, 2001, vol. 20, pp. 241-245.

2. C. Qui and R. Metselaar: J. Alloys Compounds, 1994, vol. 216, pp. 55-60.

3. S. Seetharaman: J. of Metals, Nov. 2002.

4. R. Fruehan, Y. Li and G. Carkin: Met. And Materials Trans. B, 2004, vol. 35B, pp. 617-623.

5. R. Fruehan and G. Carkin: Met. And Materials Trans. B, 2004, vol. 35B, pp. 1011-1013.

6. K. Motzfeldt, B. Sandberg, and J. Julsard: Int. Slag Symp., Stockholm, June 2000.

7. S. Degterov and A. D. Pelton: Report to Alcoa, Alcoa Technical Center, Alcoa Center, PA., Feb. 1999.

8. V. Garcia-Osorio, T. Lindstad and E. Ydstie, "Modeling Vapor Recovery in Carbothermic Aluminum Process", Light Metals, The Minerals, Metals and Material Society, February 2001.

9 V. Garcia Osorio, and B. Erik Ydstie (2004) "Vapor Recovery Reactor in Carbothermic Aluminum Production”, Che. E. Sci, Vol. 59, N0 10, pp. 2053-1064.

10. V. Garcia Osorio, and B. Erik Ydstie, "Multiphase Reaction Model for a Moving Bed Vapor Recovery Reactor”, Che. E. Sci, Under Review.

11 V. Garcia Osorio, M. RuSzkowki and B. Erik Ydstie, "Integrating Physics and Process Control Using Passivity and the Second Law of Thermodynamics", AIChE, In Press.

12. V. Garcia Osorio, and B. Erik Ydstie, "Distributed, Asynchronous and Hybrid Simulation of Process Networks Using Recording Controllers, " Int. Journal of Robust and Nonlinear Control, Vol. 14, (2004) pp 227-248

13. Dimitrios I. Gerogiorgis, and B. Erik Ydstie "An MINLP Model for the Conceptual Design of a Carbothermic Aluminium Reactor", in: Proceedings of the European Symposium on Computer-Aided Process Engineering (ESCAPE-13), Lappeenranta, Finland, pp. 131 - 136 (2003).

14. Dimitrios I. Gerogiorgis, and B. Erik Ydstie, "A Steady State CFD Simulation of a Carbothermic Reduction Reactor for the Production of Metallic Aluminium", TMS 
International Conference on the Computational Modeling of Materials, Minerals and Metals Processing, San Diego, CA, September 2001.

15. Dimitrios I. Gerogiorgis, and B. Erik Ydstie, “A Multiscale Model for Conceptual Design and Simulation of a Carbothermic Reduction Process for Aluminium Production", in: Proceedings of the Conference on Foundations Of Computer-Aided Process Operations - FOCAPO 2003, Coral Springs, FL, pp. 581 - 584 (2003).

16. Dimitrios I. Gerogiorgis, and B. Erik Ydstie, “A Finite Element Computational Fluid Dynamics Sensitivity Analysis for the Conceptual Design of a Carbothermic Aluminium Reactor", in: Light Metals 2003, The Minerals, Metals and Materials Society (TMS), Allentown, PA, pp. 407 - 414 (2003).

17. Dimitrios I. Gerogiorgis, and B. Erik Ydstie, "Process Systems Tools for Design and Optimization of Carbothermic Reduction Processes", in: Aluminum 2003, The Minerals, Metals and Materials Society (TMS), Allentown, PA, pp. 289 - 298 (2003).

18. Dimitrios I. Gerogiorgis, and B. Erik Ydstie, "Finite Element Flow Modeling in a Carbothermic Reactor”, in: Proceedings of Eurométeaux/GDMB European Metallurgical Conference (EMC 2003), Hannover, Germany, pp. 1171 - 1186 (2003).

19. Dimitrios I. Gerogiorgis, and B. Erik Ydstie, "Flow Modeling for Design of Carbothermic Aluminium Reactors", in: Proceedings of the Third International Conference on CFD in Mineral \& Process Industries, Melbourne, Australia, pp. 607-612 (2003), Winner best student paper award.

20. Dimitrios I. Gerogiorgis, and B. Erik Ydstie, "Integrated Multiphysics and Computational Fluid Dynamics Modeling of a Carbothermic Aluminium Reactor", paper accepted for publication in: Light Metals 2004, The Minerals, Metals and Materials Society (TMS), Allentown, PA (2004).

1. Dimitrios I. Gerogiorgis, and B. Erik Ydstie, "Multiscale Modeling for Electrode Voltage Optimization in the Design of a Carbothermic Aluminium Process", paper published in Proceedings of the Conference on Foundations Of Computer-Aided Process Design - FOCAPD 2004, AIChE Symposium Series, Princeton, NJ (2004). 


\section{INVENTIONS/PATENT APPLICATIONS/INVENTION REPORTS}

US 6,440,193; Method and Reactor for Production of Aluminum by Carbothermic Reduction of Alumina; August 27, 2002; Johansen and Aune.

US 6,475,260; Scrap-based Carbothermic Aluminum Production; Nov. 5, 2002; LaCamera.

US 6,530,970; Method for Recovering Aluminum Vapor and Aluminum Suboxide from Off-gases During Production of Aluminum by Carbothermic Reduction of Alumina; March 11, 2003; Lindstad.

US 6,805,723; Method and Reactor for Production of Aluminum by Carbothermic Reduction of Alumina; Oct. 19, 2004; Aune and Johansen.

US 6,849,101; Method Using Selected Carbons to React with $\mathrm{Al}_{2} \mathrm{O}$ and $\mathrm{Al}$ Vapors in the Carbothermic Production of Aluminum; Feb. 1, 2005; Fruehan, Li and Carkin.

US Application 10/646,507; Electrode Arrangement as a Substitute Bottom for an Electrothermic Slag Smelting Furnace; Aug. 23, 2003; Aune et al.

US Application 10/678,339; A Device and Method for Treatment of Gases; Oct. 10, 2003; Vegge et al.

US Application 10/932,846; Single Furnace Carbothermic Reduction; Sept. 1, 2004; Fruehan.

Invention Report 370108-00172; Carbothermic Process Control Using Slag Analyses; Oct. 22, 2004: Christini.

Invention Report 370108-00173; Increased Pressure Operation to Suppress Vapor Reactions; Oct. 26, 2004; Christini.

Invention Report 370108-00178; Metal Tapping Carbothermic Reactor; Dec. 8, 2004; Carkin. 


\section{PUBLICATIONS}

\section{Fundamental Research}

R.J. Fruehan et al, Mechanism and Rate of Reaction of $\mathrm{Al}_{2} \mathrm{O}, \mathrm{Al}$, and $\mathrm{CO}$ Vapors with Carbon, Metallurgical and Materials Transactions B, Vol. 35B, Aug. 2004, pp. 617-623.

R.J. Fruehan et al, The Pressure of $\mathrm{Al}_{2} \mathrm{O}$ and $\mathrm{Al}$ in Equilibrium with a $\mathrm{Al}_{2} \mathrm{O}-\mathrm{Al}_{4} \mathrm{C}_{3}$ (Saturated) Slag at $1950^{\circ} \mathrm{C}$ to $2020^{\circ} \mathrm{C}$, Metallurgical and Materials Transactions B, Vol. 35B, Oct. 2004, pp. 1011-1013.

\section{Process Development}

M.J. Bruno, Aluminum Carbothermic Technology Comparison to Hall-Heroult Process, Light Metals 2003, March 2003, pp. 395-400.

K. Johansen et al, Aluminum Carbothermic Technology Alcoa-Elkem Advanced Reactor Process, Light Metals 2003, March 2003, pp. 401-406.

H. Myklebust et al, Greenhouse Gas Emissions from Aluminum Carbothermic Technology Compared to Hall-Heroult Technology, Light Metals 2005, Feb. 2005, pp. 519-522.

\section{Computer Modeling}

V. Garcia-Osorio et al, Modeling Vapor Recovery in Carbothermic Aluminum Process, Light Metals 2001, Feb. 2001, pp. 227-237.

V. Garcia-Orsorio et al, Dynamic Model for Vapor Recovery in Carbothermic Aluminum Process, Computational Modeling of Materials, Minerals, Metals Processing, Sept. 2001, pp. 301-310.

V. Garcia-Orsorio et al, Vapor recovery reactor in Carbothermic Aluminum Production, Che. E. Sci., Vol. 59, No 10, 2004, pp. 2053-1064.

V. Garcia-Orsorio et al, Distributed, asynchronous and hybrid simulation of process networks using recording controllers, Int. Journal of Robust and Nonlinear Control, Vol. 14, (2004) pp 227-248.

Dimitrios I. Gerogiorgis, et al, Thermophysical Property Modeling for Multicomponent Molten Slags at High Temperatures, in: Proceedings of the Third Panhellenic Scientific Conference on Chemical Engineering, NCSR "Demokritos", Athens, Greece, pp. 73 - 76 (2001).

Dimitrios I. Gerogiorgis et al, A Steady State CFD Simulation of a Carbothermic Reduction Reactor for the Production of Metallic Aluminium, in: Proceedings of the Third 
Panhellenic Scientific Conference on Chemical Engineering, NCSR "Demokritos", Athens, Greece, pp. 233 - 236 (2001).

Dimitrios I. Gerogiorgis et al., A Steady State Electrothermic Simulation Analysis of a Carbothermic Reduction Reactor for the Production of Aluminium, in: Proceedings of the TMS Meeting on the Computational Modeling of Materials, Minerals and Metals Processing (TMS2002), Seattle, WA, pp. 273-282 (2001).

Dimitrios I. Gerogiorgis et al, Finite Element Modeling and Simulation of Flow in a Conceptual Carbothermic Aluminium Reactor, in: Proceedings of the Ninth Annual International Conference on Composites Engineering (ICCE/9), Wyndham Emerald Plaza Hotel, San Diego, CA, pp. 233 - 234 (2002).

Dimitrios I. Gerogiorgis et al, A Multiscale Model for Conceptual Design and Simulation of a Carbothermic Reduction Process for Aluminium Production, in: Proceedings of the Conference on Foundations Of Computer-Aided Process Operations - FOCAPO 2003, AIChE Symposium Series, Coral Springs, FL, pp. 581 - 584 (2003).

Dimitrios I. Gerogiorgis et al, A Finite Element Computational Fluid Dynamics Sensitivity Analysis for the Conceptual Design of a Carbothermic Aluminium Reactor, in: Light Metals 2003, The Minerals, Metals and Materials Society (TMS), Allentown, PA, pp. 407414 (2003).

Dimitrios I. Gerogiorgis et al., Process Systems Tools for Design and Optimization of Carbothermic Reduction Processes, in: Aluminum 2003, The Minerals, Metals and Materials Society (TMS), Allentown, PA, pp. 289 - 298 (2003).

Dimitrios I. Gerogiorgis et al, An Introductory Lecture Series on the Theory \& Applications of Computational Fluid Dynamics in the Graduate Studies Program of the Department of Chemical Engineering at Carnegie Mellon University, in: Proceedings of the Fourth Panhellenic Scientific Conference on Chemical Engineering, University of Patras Convention Center, Patras, Greece, pp. 565 - 568 (2003).

Dimitrios I. Gerogiorgis et al, A Steady State CFD Sensitivity Analysis Study for Design of a Carbothermic Aluminium Reactor, in: Proceedings of the Fourth Panhellenic Scientific Conference on Chemical Engineering, University of Patras Convention Center, Patras, Greece, pp. 665 - 668 (2003).

Dimitrios I. Gerogiorgis et al, Mixed-Integer Nonlinear Programming (MINLP) for Design of a Carbothermic Aluminium Reactor, in: Proceedings of the Fourth Panhellenic Scientific Conference on Chemical Engineering, University of Patras Convention Center, Patras, Greece, pp. 733 - 736 (2003).

Dimitrios I. Gerogiorgis et al, An MINLP Model for the Conceptual Design of a Carbothermic Aluminium Reactor, in: Proceedings of the European Symposium on 
Computer-Aided Process Engineering (ESCAPE-13), Lappeenranta, Finland, pp. 131 - 136 (2003).

Dimitrios I. Gerogiorgis et al, Finite Element Flow Modeling in a Carbothermic Reactor, in: Proceedings of Eurométeaux/GDMB European Metallurgical Conference (EMC 2003), Hannover, Germany, pp. 1171 - 1186 (2003).

Dimitrios I. Gerogiorgis et al, Flow Modeling for Design of Carbothermic Aluminium Reactors, in: Proceedings of the Third International Conference on CFD in Mineral \& Process Industries, Melbourne, Australia, pp. 607 - 612 (2003).

Dimitrios I. Gerogiorgis et al, Integrated Multiphysics and Computational Fluid Dynamics Modeling of a Carbothermic Aluminium Reactor, paper accepted for publication in: Light Metals 2004, The Minerals, Metals and Materials Society (TMS), Allentown, PA (in press -2004).

Dimitrios I. Gerogiorgis et al, Multiscale Modeling for Electrode Voltage Optimization in the Design of a Carbothermic Aluminium Process, paper accepted for publication in: Proceedings of the Conference on Foundations Of Computer-Aided Process Design FOCAPD 2004, AIChE Symposium Series, Princeton, NJ (in press - 2004). 